\title{
Dynamic crushing behavior of a multilayer thin-walled aluminum corrugated core: The effect of velocity and imperfection
}

\author{
Mustafa Sarıkaya, Alper Taşdemirci, Mustafa Güden* \\ Dynamic Testing and Modeling Laboratory and Department of Mechanical Engineering, Izmir Institute of Technology, Gülbahçe Köyü, Urla, Izmir, Turkey
}

\section{A R T I C L E I N F O}

\section{Keywords:}

Corrugated core

SHPB

Direct impact test

Shock deformation

Modelling

\begin{abstract}
A B S T R A C T
The crushing behavior of a multilayer $1050 \mathrm{H} 14$ aluminum corrugated core was investigated both experimentally and numerically (LS-Dyna) using the perfect and imperfect models between 0.0048 and $90 \mathrm{~m} \mathrm{~s}^{-1}$. The dynamic compression and direct impact tests were performed in a compression type and a modified Split Hopkinson Pressure Bar set-up, respectively. The investigated fully imperfect model of the corrugated core sample represented the homogenous distribution of imperfection, while the two-layer imperfect model the localized imperfection. The corrugated core experimentally deformed by a quasi-static homogenous mode between 0.0048 and $22 \mathrm{~m} \mathrm{~s}^{-1}$, a transition mode between 22 and $60 \mathrm{~m} \mathrm{~s}^{-1}$ and a shock mode at $90 \mathrm{~m} \mathrm{~s}^{-1}$. Numerical results have shown that the stress-time profile and the layer crushing mode of the homogeneous and transition mode were well predicted by the two-layer imperfect model, while the stress-time profile and the layer crushing mode were well approximated by the fully imperfect model. The fully imperfect model resulted in complete sequential layer crushing at 75 and $90 \mathrm{~m} \mathrm{~s}^{-1}$, respectively. The imperfect layers in the shock mode only affected the distal end stresses, while all models implemented resulted in similar impact end stresses. The distal end initial crushing stress increased with increasing velocity until about $22 \mathrm{~m} \mathrm{~s}^{-1}$; thereafter, it saturated at $\sim 2 \mathrm{MPa}$, which was ascribed to the micro inertial effect. Both the stress-time and velocity-time history of the rigidperfectly-plastic-locking model and the critical velocity for the shock deformation were well predicted when a dynamic plateau stress determined from the distal end stresses in the shock mode was used in the calculations.
\end{abstract}

\section{Introduction}

The experimental and numerical studies on the dynamic crushing behavior of cellular metals [1], including aluminum honeycombs and foams, have clarified three distinct deformation modes at increasing velocities [2-10]. Between quasi-static and low velocity range, the structure deforms by forming random, non-contiguous crush bands. The crushing initiates at the weakest region in the interior of the sample [11]. This deformation mode is referred to as the quasi-static homogenous crushing mode [3], because the stress at the impact end (proximal end) is almost equal to the stress at the distal end (rear end) [6]. A transition mode occurs at intermediate velocities. In this mode, the crush bands form non-contiguously near the impact end and attain the local strains less than the densification strain. A shock mode appears above a critical velocity. The shock mode of deformation is characterized by the propagation of sequential, planar crush bands (one cell size wide) starting from the impact end $[7,11]$. The shock mode imposes an impact end stress far greater than the distal end stress and the difference between them increases as the impact velocity increases. The inertial effects associated with the shock formation were reported to be responsible for the stress enchantment above the critical velocity, while the micro inertial effects were ascribed to the stress enchantment below the critical velocity in cellular structures [11-13]. The micro inertial effects on the stress enhancement was reported to be relatively weak especially in the high velocity regime where the inertial effects associated with the shock formation were dominant $[6,11]$.

The previous experimental and numerical studies on the metallic cellular structures have been mostly on the aluminum regular and irregular honeycomb and Voronoi structures [2,5-8,14-16] and aluminum open and closed cell foams [17-23]. However, there have been few studies on the corrugated structures [24-26]. The dispersion in the strength of aluminum closed cell foams is also as high as $20 \%$ which may cover the increase in strength at increasing strain rates/velocities [27]. The numerical models of cellular structures are usually constructed in perfect geometry, while the real structures always contain imperfections. Since the imperfections tend to reduce the cell wall bending and buckling stresses, the perfect geometry models overestimate the actual strength of structure. Various numerical methods of

\footnotetext{
* Corresponding author.

E-mail address: mustafaguden@iyte.edu.tr (M. Güden).
} 

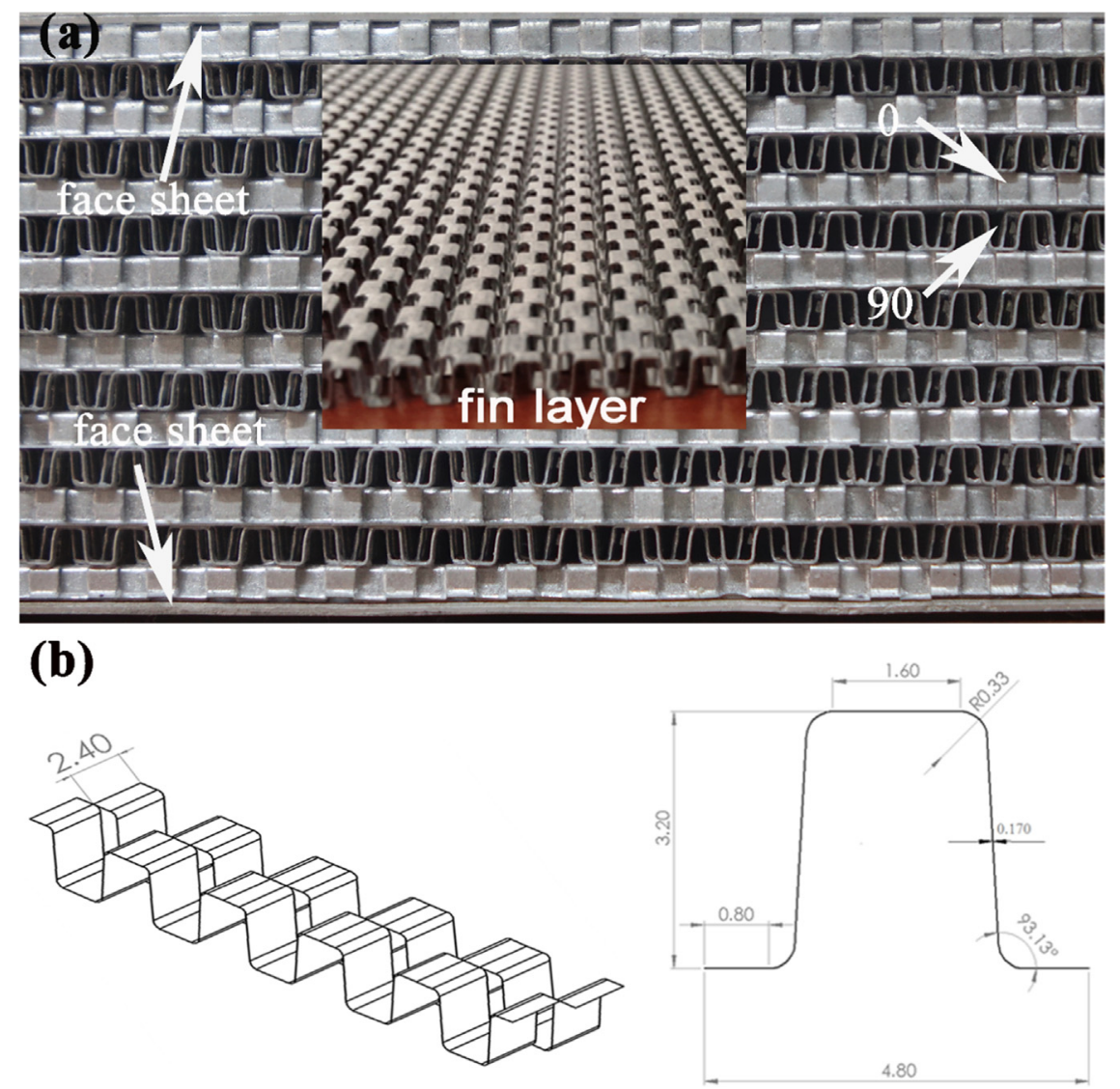

Fig. 1. (a) The cross-section of multilayered sandwich core and a fin layer and (b) The technical drawing showing the dimensions.
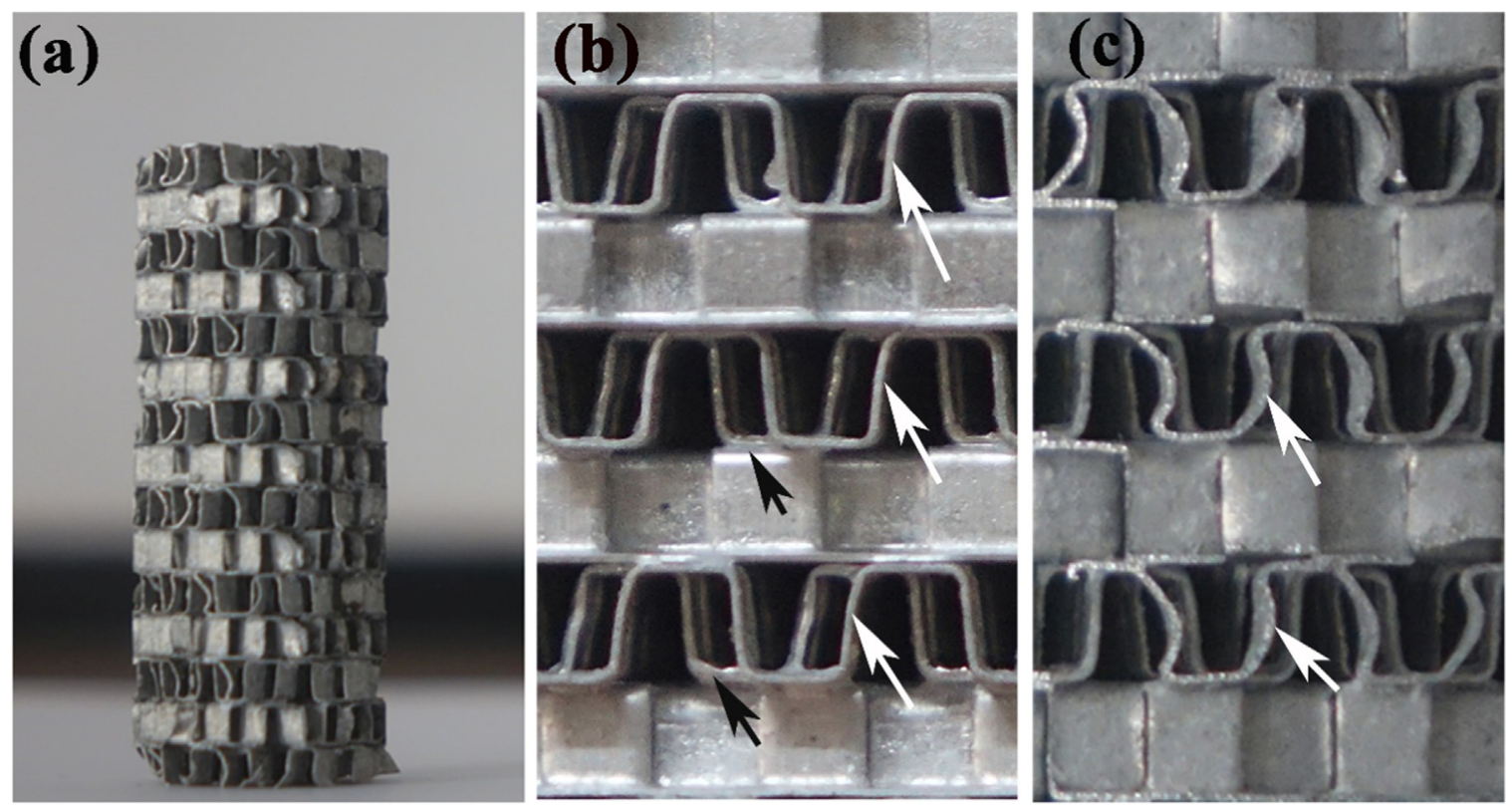

Fig. 2. (a) Test sample, (b) Slightly bent-fin walls (white arrows) and increased thickness at contact regions (black arrows) of the as-received sandwich core and (c) The bent-fin walls at the outer surface of sample after machining.

forming imperfections have also been reported including distortion in the mesh, node shaking, pre-buckling of cell walls, modelling the actual size of cell wall [28], implementing random mechanical properties [29] and deflection in truss strut [30].

The present study aims to investigate both experimentally and numerically the effect of imperfections on the compression and impact deformation of an aluminum corrugated sandwich core at various velocities. The chosen imperfection geometry in present study resulted from the machining and was larger in size than those existed in the asreceived sandwich core. The investigated corrugate core was made of multilayer corrugated fin layers and previously shown to exhibit repeatable responses to mechanical forces [24,26,31]. This allows 


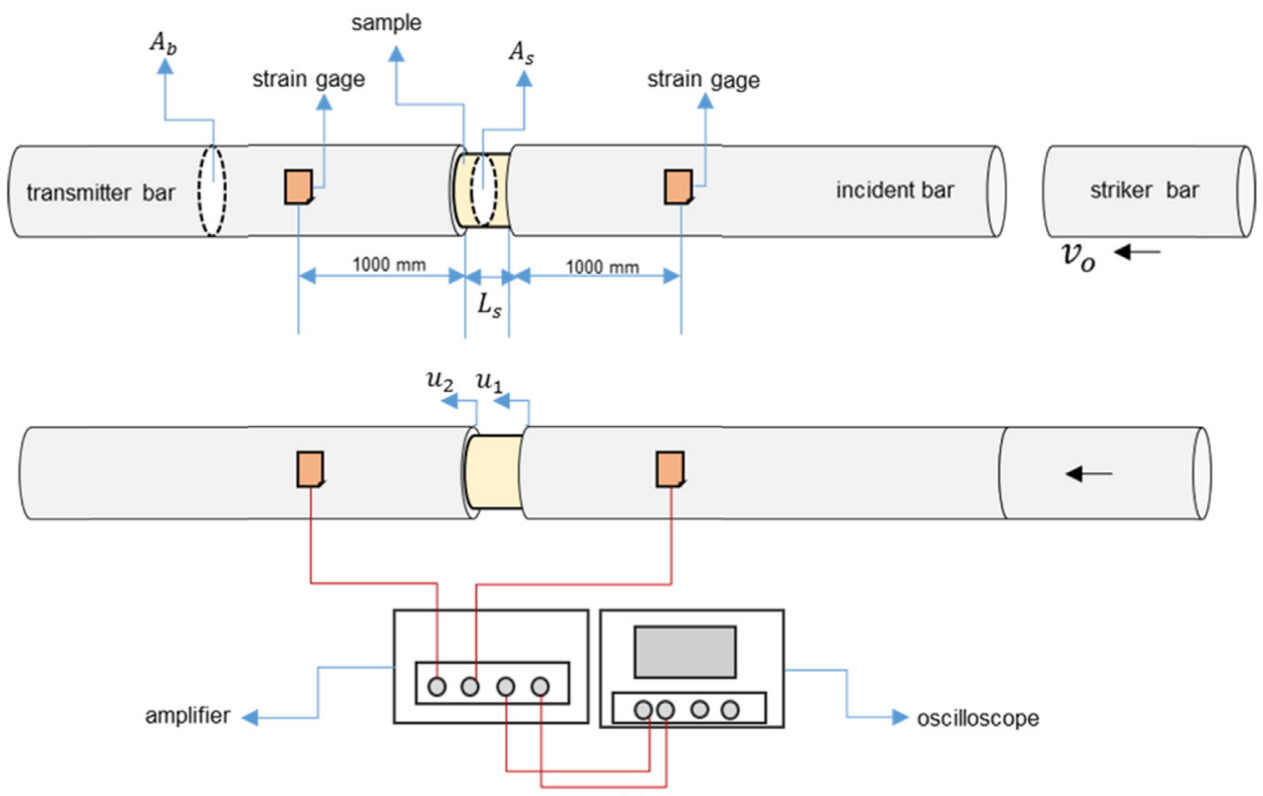

(a)

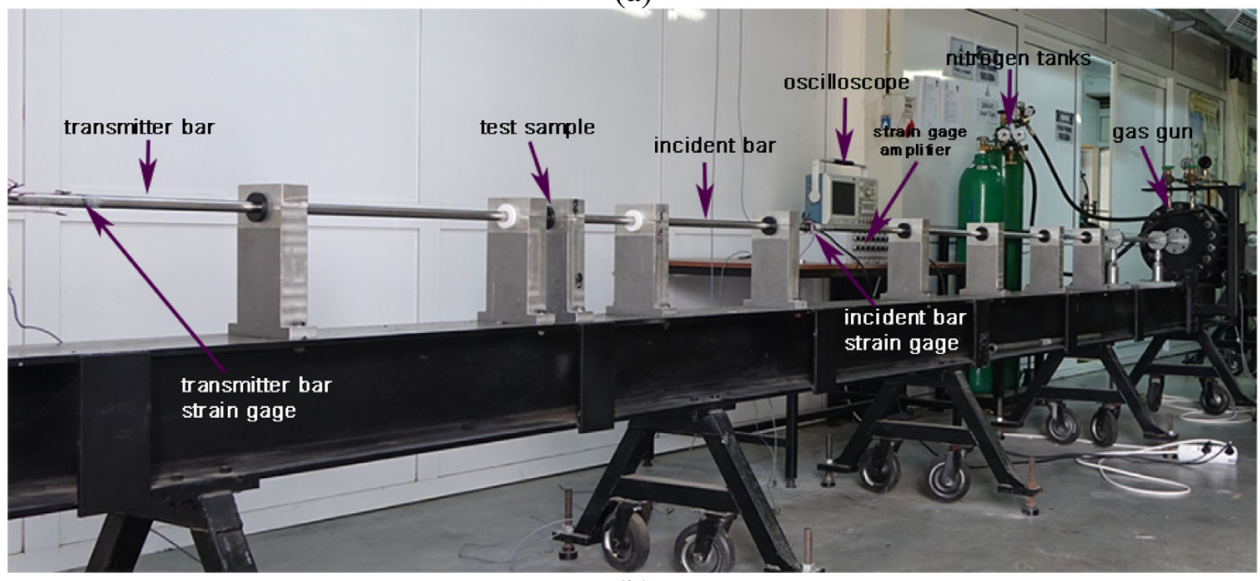

(b)

Fig. 3. (a) The schematic of SHPB test and (b) The picture of the used SHPB test set-up.

accurate determination of the effect of strain rate on the mechanical properties. Also, the layered structure makes it possible to construct a 3D model in order to monitor the strain and velocity histories of each layer during crushing. In present study, the quasi-static compression tests were performed at $4.8 \times 10^{-3} \mathrm{~m} \mathrm{~s}^{-1}$, the Split Hopkinson Pressure Bar (SHPB) tests at 6 and $10 \mathrm{~m} \mathrm{~s}^{-1}$ and the direct impact tests between 9 and $90 \mathrm{~m} \mathrm{~s}^{-1}$. Three-dimensional finite element models of the tests were developed in LS-Dyna. The validity of the models was discussed along with the experimental and numerical stress-time and the numerical layer strain-time and velocity-time histories.

\section{Materials and testing}

The investigated cellular structure was made of $1050 \mathrm{H} 14 \mathrm{Al}$ trapezoidal zig-zag corrugated layers (15 fins) as seen in Fig. 1(a). The height, width, length and thickness of a fin are sequentially $3.20,1.6$, 2.4 and $0.170 \mathrm{~mm}$ (Fig. 1(b)). The processing details of fin layers and sandwich core are given elsewhere [32]. The multilayer corrugated sandwich plate shown in Fig. 1(a) is $500 \times 500 \times 50 \mathrm{~mm}$ in size and assembled in $0 / 90$ fin layer configuration (Fig. 1(a)). The face sheets, $1 \mathrm{~mm}$-thick $1050 \mathrm{H} 14 \mathrm{Al}$ sheet as shown in Fig. 1(a), prevent the layers from the mechanical damaging during brazing and subsequent machining.

The test samples were extracted from a sandwich plate by means of an electro-discharge machine. The picture of a cylindrical compression test sample with a diameter of $19.40 \mathrm{~mm}$ is shown in Fig. 2(a). The test sample had a height of $48 \mathrm{~mm}$ and a density of $326 \mathrm{~kg} \mathrm{~m}^{-3}$ without face sheets. In the SHPB tests, the samples were tested without face sheets, while in the direct impact tests the samples were tested with a face sheet on the incident bar side (distal end) in order to make a full contact of the sample with the end-face of the incident bar using a thin layer of grease. The test sample shown in Fig. 2(a) contains typical fin wall imperfections induced in brazing and cutting. The fin walls are slightly bent (white arrows in Fig. 2(b)) in the as-received sandwich core. During sample cutting, the fins at the outer surface of the sample deformed extensively (white arrows in Fig. 2(c)). These imperfections are likely to change the crushing behavior and crushing stress. In order to account the effect of fin wall imperfections as explained in the modelling section a bending type imperfection was introduced to the fin layers. In addition, the fin walls are determined to be thicker at the fin layer contact sites (black arrows in Fig. 2(b)), which is ascribed to the accumulation of brazing filler material $(7 \mathrm{wt} \%)$. The thicker contacts are further anticipated to affect the densification strain as well as the crushing stress and will be investigated separately.

Since the simulation time substantially increased at relatively low quasi-static strain rates, the quasi-static compression tests were performed at the nominal strain rate of $10^{-1} \mathrm{~s}^{-1}\left(4.8 \times 10^{-3} \mathrm{~m} \mathrm{~s}^{-1}\right)$. A video extensometer synchronized with the Shimadzu universal test 


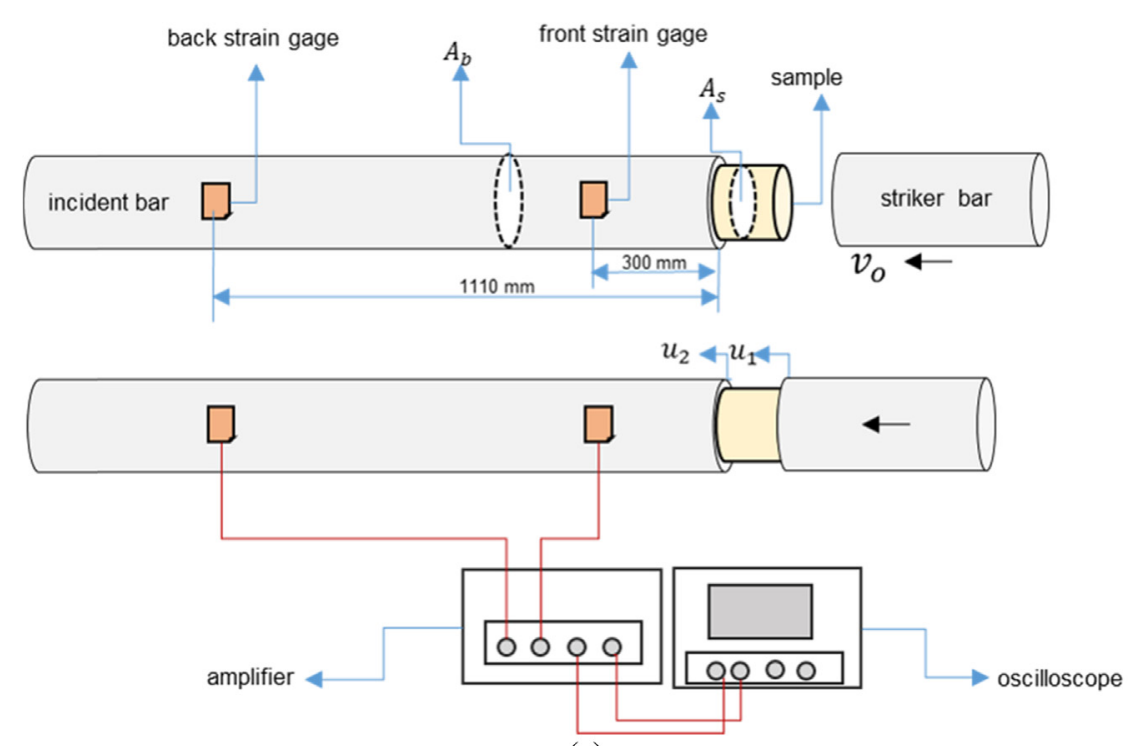

(a)

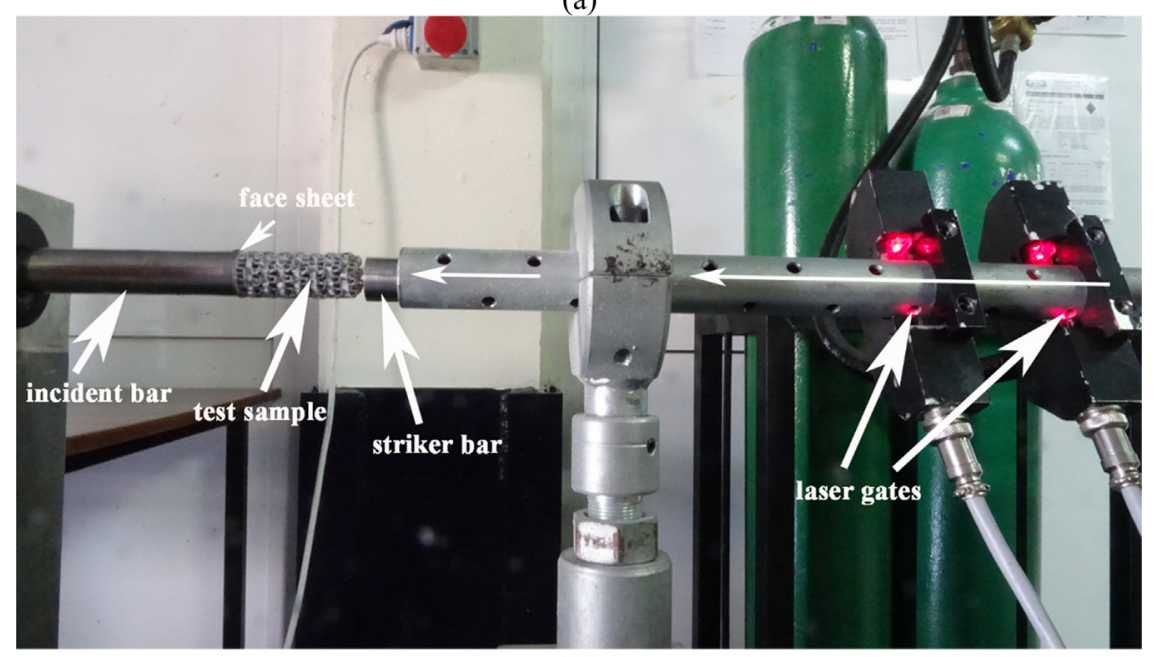

(b)

Fig. 4. (a) The schematic of direct impact test and (b) The picture of the used direct impact test set-up.
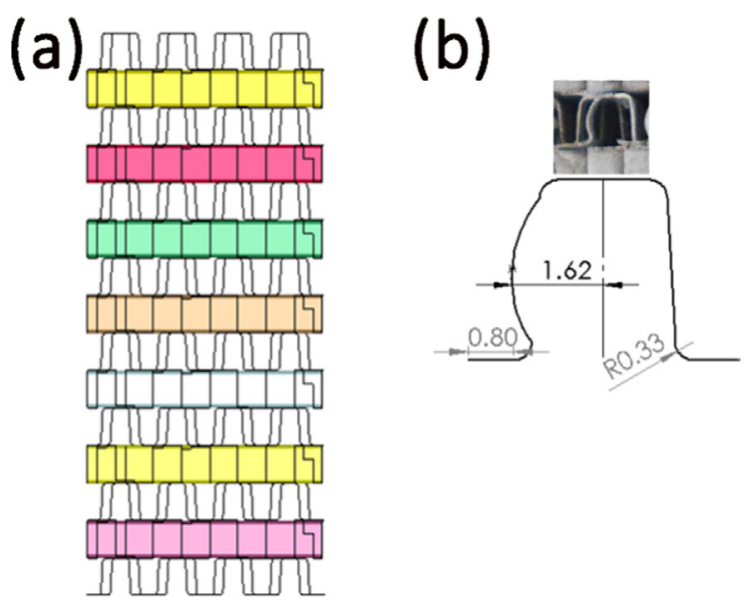

(c)
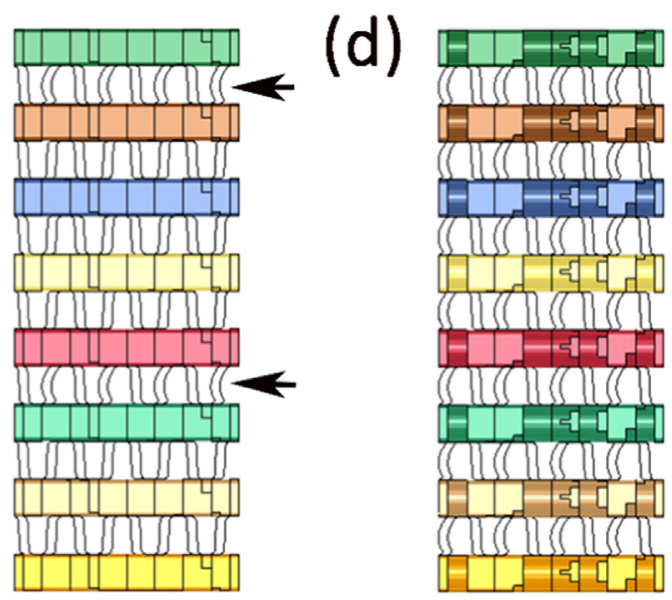

Fig. 5. (a) Perfect model, (b) Imperfect unit fin geometry, (c) Two-layer imperfect model and (d) Fully imperfect model.

machine was used to record the displacement. The deformation of the samples was recorded using a video camera in order to monitor the crush band initiation and progression. Two different dynamic tests were conducted: the SHPB and direct impact test. In the SHPB test, the sample was tested in a conventional compression SHPB apparatus. In the direct impact test, the sample was inserted in front of the incident bar and the striker bar directly impinged onto the sample.

The schematic and the picture of the used SHPB set-up are shown in Fig. 3(a) and (b), respectively. In a typical test, the sample is sandwiched between the incident and transmitter bars. After the impact of 
(a)
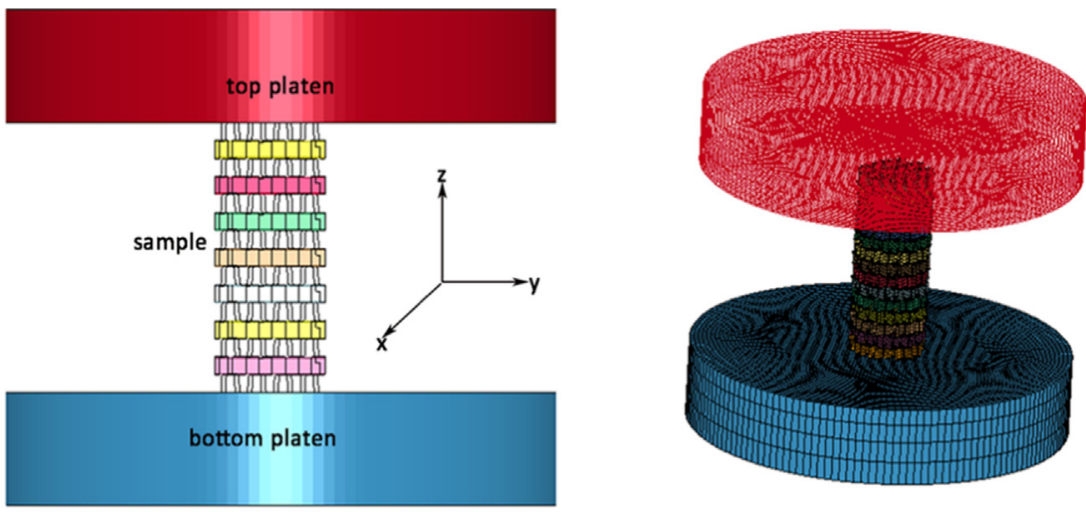

(b)

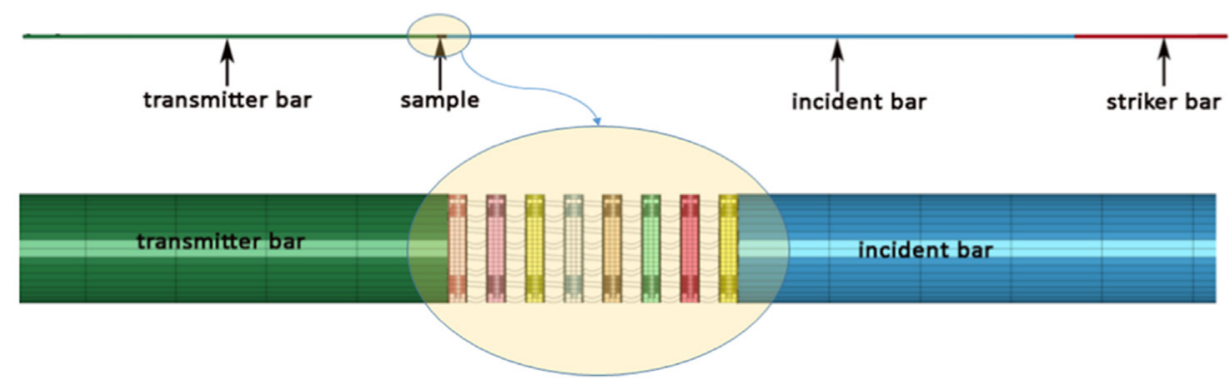

(c)

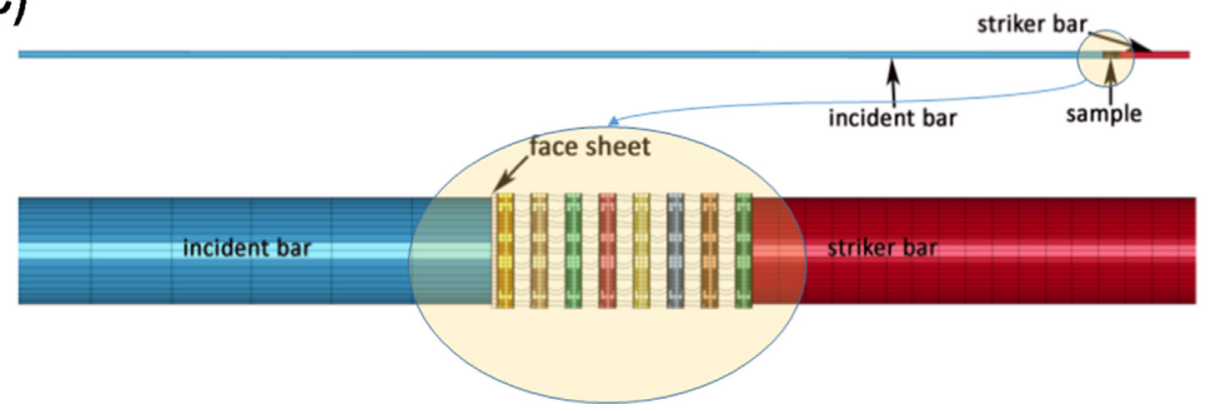

Fig. 6. (a) Front and 3D views of the numerical model of quasi-static compression test, (b) SHPB test model and (c) The direct impact test model.

the striker bar to the incident bar, a rectangular elastic compressive stress wave starts to propagate on the incident bar. The propagating stress wave is partly reflected as a tensile wave into the incident bar and partly transmitted to the transmitter bar as a compressive wave at the sample/bar interfaces. The incident, reflected and transmitted wave strains on the bars are measured at a same distance from the sample/ bar interfaces by means of a full-bridge strain gage, a strain gage amplifier and an oscilloscope (Fig. 3(a)). The strain $\left(\varepsilon_{s}\right)$ and stress $\left(\sigma_{s}\right)$ of the sample are calculated using the one dimensional elastic stress wave propagation in long bars as [33]

$\varepsilon_{S}(t)=\frac{-2 c \int_{0}^{\tau} \varepsilon_{R} d t}{L_{S}}$

and

$\sigma_{s}(t)=\frac{A_{b} E \varepsilon_{T}}{A_{s}}=\frac{A_{b} E\left(\varepsilon_{I}+\varepsilon_{R}\right)}{A_{s}}=\frac{A_{b} E\left(\varepsilon_{T}+\varepsilon_{I}+\varepsilon_{R}\right)}{2 A_{s}}$

respectively. In Eqs. 1 and 2, $c$ is the elastic wave velocity of the bar, $L_{s}$ is the length of the sample, $t$ is the time, $\varepsilon_{R}, \varepsilon_{I}$ and $\varepsilon_{T}$ are sequentially the reflected, incident and transmitted strains, $A_{b}$ and $A_{s}$ are sequentially the cross-section area of the bar and the sample and $E$ is the elastic modulus of the bar. The first, second and third equations in Eq.2 are sequentially the one-, two- and three-wave solution of stress [34]. The strain rate is calculated using the following relation

$\dot{\varepsilon_{S}}(t)=\frac{-2 c \varepsilon_{R}}{L_{S}}$

In the tests, the strain on the bars was calculated using the following full-bridge strain gage circuit relation

$\varepsilon=\frac{2 \int \varepsilon(V) d t}{G K V(1+\mu)}$

where, $\varepsilon(V), G, K, V$ and $\mu$ are the strain voltage reading, the strain gage amplifier gain, strain gage factor, excitation voltage of the strain gage bridge and Poisson's ratio of the bar material, respectively. The SHPB apparatus consisted of a $19.40 \mathrm{~mm}$ diameter Inconel $718 \mathrm{bar}$; $3110 \mathrm{~mm}$-long incident bar, $2050 \mathrm{~mm}$-long transmitter bar and 500 and $750 \mathrm{~mm}$-long striker bars (Fig. 3(b)). The velocity of the striker bar in the tests was $\sim 6 \mathrm{~m} \mathrm{~s}^{-1}$ for $750 \mathrm{~mm}$ - and $\sim 10 \mathrm{~m} \mathrm{~s}^{-1}$ for $500 \mathrm{~mm}$-long striker bars. The values of $G, K$ and $V$ were $20,2.09$ and $10 \mathrm{~V}$, respectively. The sample deformation was captured by a Fastcam Photron 


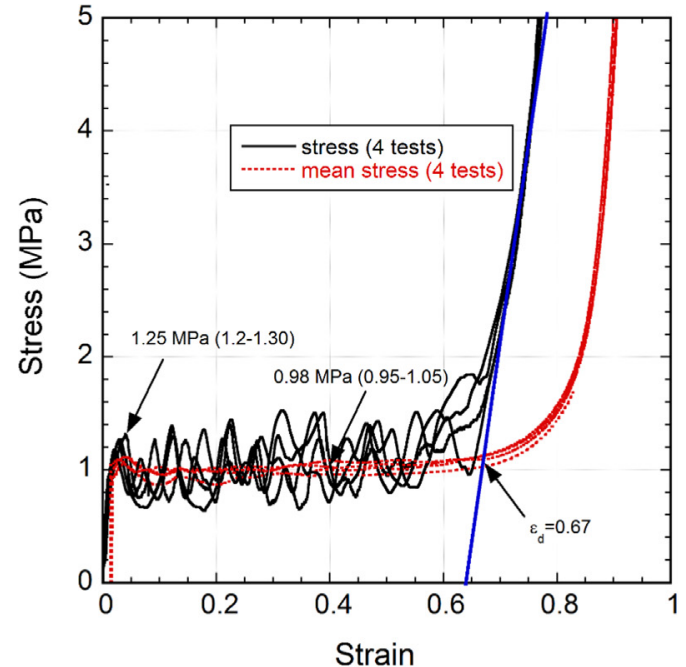

(a)

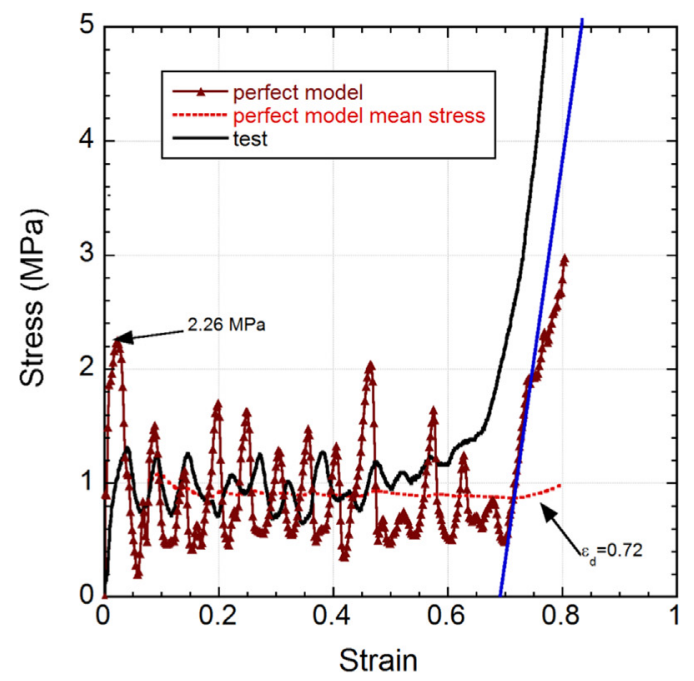

(b)

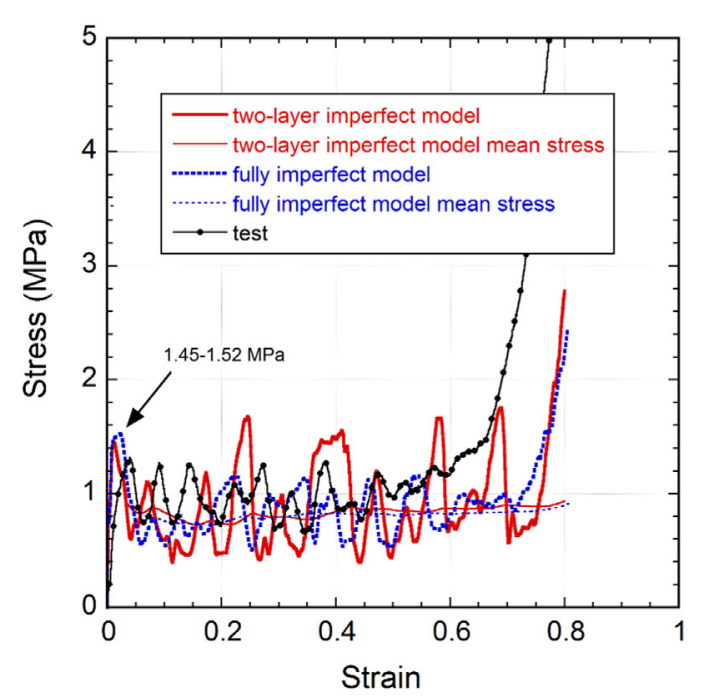

(c)

Fig. 7. Quasi-static (a) Test stress-strain and mean stress-strain curves, (b) Perfect model and test stress-strain curves and (c) Fully imperfect models and test stress-strain curves. high speed camera at 20,000 fps.

The schematic of direct impact test is shown in Fig. 4(a). The stress and strain analyses in this test are based on the assumption of that there is a stress equilibrium between incident bar/sample and striker bar/ sample interfaces when the cross-sectional areas of the incident and striker bars are the same (Fig. 4(a)). Then, the strain of the sample is [35]

$\varepsilon_{S}(t)=\frac{v_{0} t-2 c \int_{0}^{\tau} \varepsilon_{I}{ }^{*} d t}{L_{S}}$

where, $\varepsilon_{I}^{*}$ is the induced strain on the incident bar and $v_{o}$ is the initial velocity of the striker bar. Since the strain on the incident bar was comparably small due to the low mechanical impedance of the corrugated sample, the nominal strain of the sample was calculated using the flowing relation

$\varepsilon_{S}(t)=\frac{v_{o} t}{L_{s}}$

The stress at the incident bar/sample contact is

$\sigma_{i}(t)=\frac{A_{b} E \varepsilon_{I}^{*}}{A_{s}}$

In the test, the sample was attached to the center of the end of the incident bar using a thin layer of grease which was strong enough to hold the sample until the impact of the striker bar (Fig. 4(b)). The strain on the incident bar used to determine the incident bar/sample contact stress was measured using two full-bridge strain-gage circuits: one is $300 \mathrm{~mm}$ and other $1110 \mathrm{~mm}$ away from the incident bar end (Fig. 4(a)). The former gage is coded as the front strain gage and the latter as the back strain gage (Fig. 4(a)). The striker bar velocity was measured just before the impact using two laser diodes placed at the exit of the gas gun barrel (Fig. 4(b)). The velocity of the striker bar having the same diameter with the incident bar $(19.40 \mathrm{~mm})$ varied between 9 and $90 \mathrm{~m} \mathrm{~s}^{-1}$. An Inconel striker bar of $250 \mathrm{~mm}$-long was used for the tests at $9 \mathrm{~m} \mathrm{~s}^{-1}$ and $22 \mathrm{~m} \mathrm{~s}^{-1}$, the 1050 aluminum striker bars of $200 \mathrm{~mm}$ long and $100 \mathrm{~mm}$-long for the tests at $40 \mathrm{~m} \mathrm{~s}^{-1}$ and $60 \mathrm{~m} \mathrm{~s}^{-1}$, respectively and a wood striker bar of $200 \mathrm{~mm}$-long for the tests at $90 \mathrm{~m} \mathrm{~s}^{-1}$.

\section{Numerical models}

The perfect fin sample model shown in Fig. 5(a) is composed of 34942 elements. In the imperfect models, a bent-type imperfection $3.2 \mathrm{~mm}$ in length and $1.6 \mathrm{~mm}$ in radius determined from the micrographs of a machined sample (Fig. 5(b)) was inserted into the fin layers. In the two-layer imperfect sample model the 2nd and 10th layer (from the top of the sample) were constructed using the bent-unit cells (black arrows in Fig. 5(c)), while in the fully imperfect model all layers were made of the bent-unit cells (Fig. 5(d)). The fully imperfect model is also considered as a homogenously distributed imperfection model, while two-layer imperfect model as the localized imperfection model. The two-layer imperfect model and fully imperfect model consisted of 33,570 and 41,921 shell elements, respectively.

The trapezoidal corrugated fin layers were meshed using Belytschko-Tsay shell elements $(0.25 \times 0.25 \mathrm{~mm})$ with five integration points and $1050 \mathrm{Al}$ face sheets were meshed using the constant stress solid elements. Previously a mesh sensitivity analysis were performed on a similar corrugated structure using three different element sizes: $0.25 \times 0.25,0.375 \times 0.375$ and $0.75 \times 0.75 \mathrm{~mm}$ [26]. It was found that all mesh sizes resulted in similar stress-strain behavior with the test at a quasi-static strain rate, while the densification strain varied slightly with the mesh size. The used mesh size however resulted in similar densification strain with the test. The increased number of integration points in shell elements lead to prolonged CPU calculation times. On the other side, the number of integration points should be higher than two in order to increase the accuracy of the models, when the buckling is 

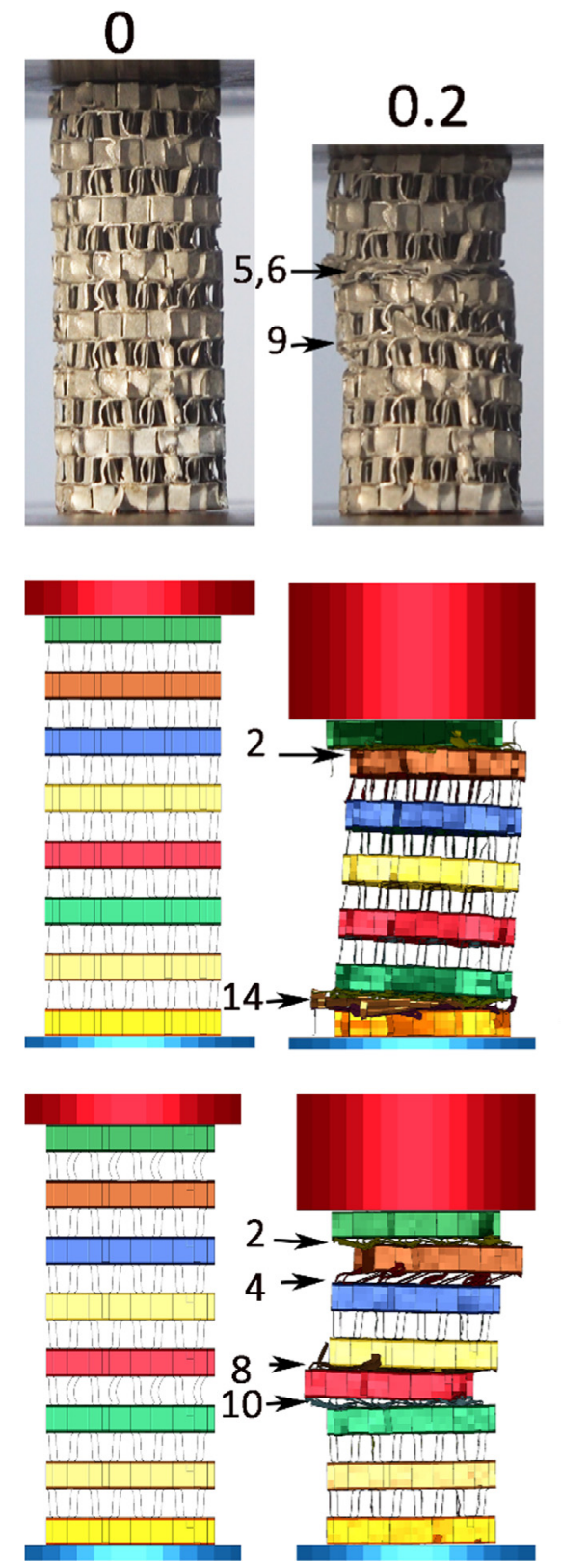

(a)

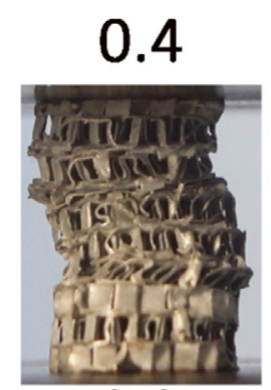

(b)
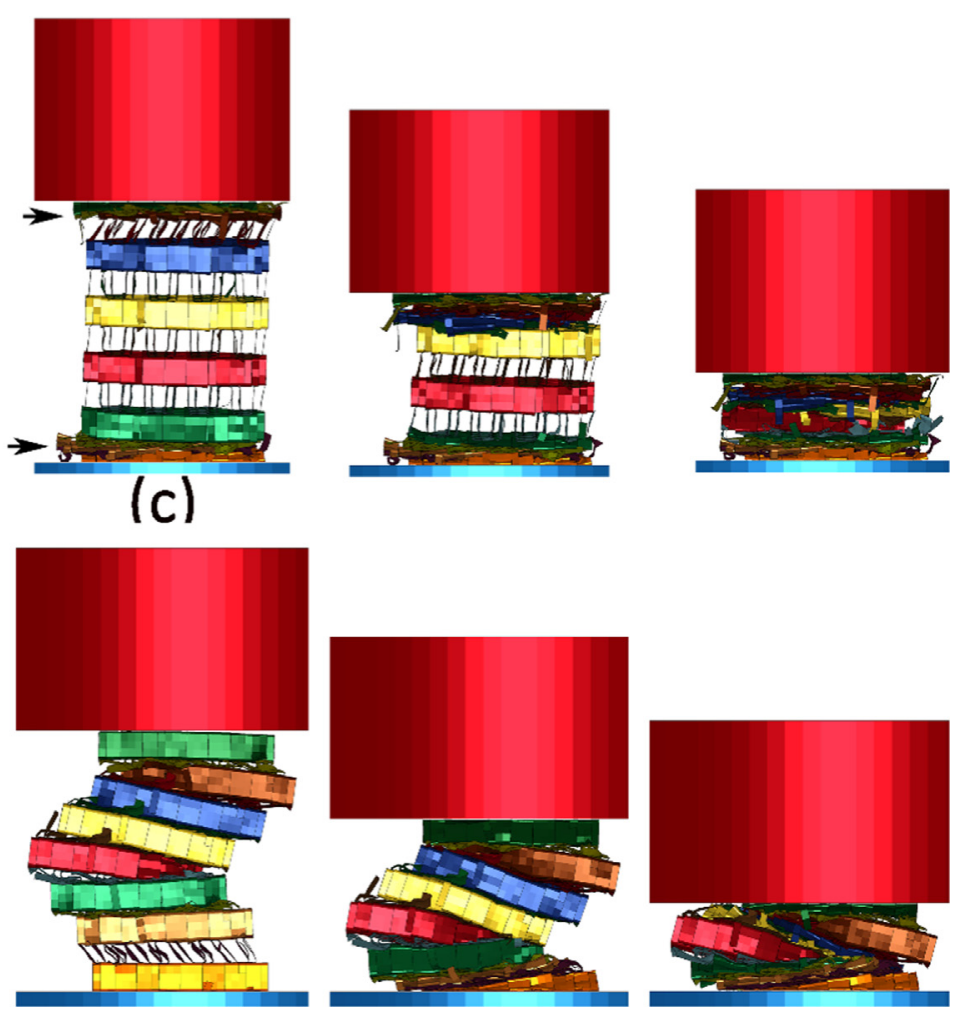

Fig. 8. Deformation pictures of corrugated sample at various strains (a) Test, (b) Perfect model and (c) Two-layer imperfect model.

the dominant deformation mode [36]. In addition, the FE meshes of the corrugated fin layers and face sheets had to coincide with each other in order to be able to define contacts. These naturally limit the use of arbitrary-defined mesh distribution and elements size.

The $1050 \mathrm{Al}$ aluminum alloy was modeled using MAT_SIMPLIFIED_JOHNSON_COOK (Material type 98) material model. The equivalent stress $\left(\sigma_{e}\right)$ in the Johnson and Cook (JC) flow stress model is given as [37]

$\sigma_{e}=\left[A+B \varepsilon_{p}^{n}\right]\left[1+\operatorname{Cln} \dot{\varepsilon}_{p}^{*}\right]\left[1-T_{H}^{m}\right]$

where $\varepsilon_{p}$ is the equivalent plastic strain, $\dot{\varepsilon}_{p}^{*}$ is the strain rate ratio given as $\frac{\dot{\varepsilon}_{p}}{\dot{\varepsilon}_{0}}$, where $\dot{\varepsilon}_{p}$ is the equivalent plastic strain rate and $\dot{\varepsilon}_{o}$ is the reference equivalent plastic strain rate, and $T_{H}$ is the normalized temperature expressed as $T=\frac{T-T_{r}}{T_{m}-T_{r}}$; where $T, T_{r}$ and $T_{m}$ are the temperature, room temperature and melting temperature, respectively. Material type 98 does not take into account the effect of temperature and aluminum alloys have no or negligible strain rate dependent flow stress; therefore, only the first bracket of Eq. (8) is taken into account. The material model parameters of $1050 \mathrm{H} 14 \mathrm{Al}$ were determined previously and $\mathrm{A}=102 \mathrm{MPa}, \mathrm{B}=98 \mathrm{MPa}$ and $\mathrm{n}=0.18$ [25].

Fig. 6(a) shows the front and 3D view of the numerical model of quasi-static compression test set-up. The model consists of the top and bottom compression test steel platen and sample. Each compression test platen was modeled with 38,400 constant stress solid and MAT20_RIGID material model ( $\mathrm{E}=210 \mathrm{GPa}$ and $\mu=0.3$ ). The rotations and translations of the compression platens were fully constrained, except the axial motion of the top platen in the z-direction. The axial velocity (z-direction) of the top platen was kept constant, the same as the tests, and defined by PRESCRIBED_MOTION_RIGID card. The contact between compression test platens and specimen was defined by AUTOMATIC_SURFACE_TO SURFACE contact. Since the total CPU time for the quasi-static test solutions are relatively long [38], the mass scaling was applied in the quasi static simulations by defining a positive time step value in CONTROL_TIMESTEP card. The mass was added or removed from the elements. In order to determine the mass scaling factor, the simulation was initially run without mass scaling and the 


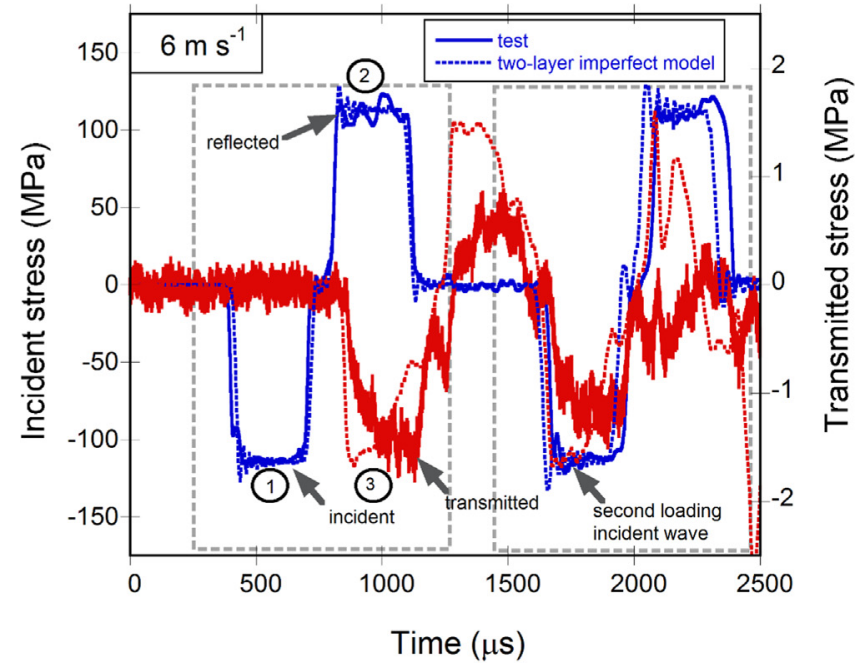

(a)

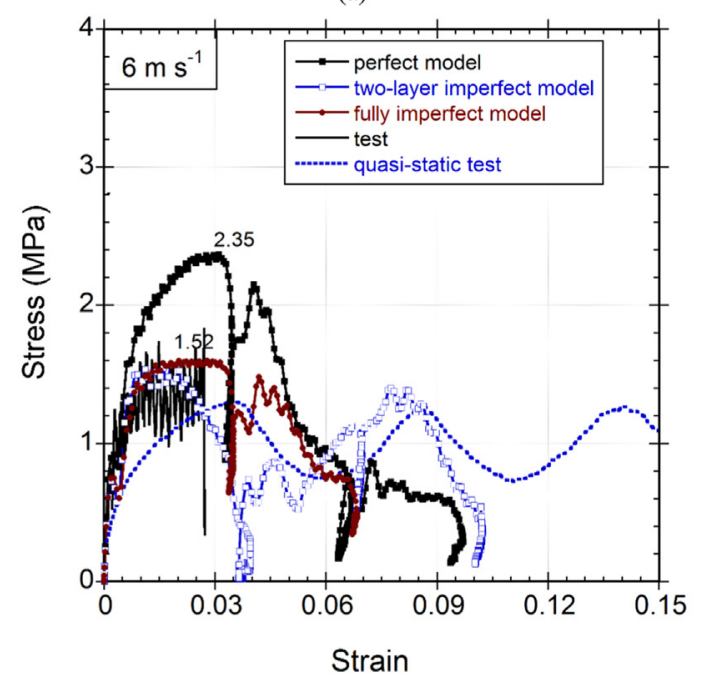

(b)

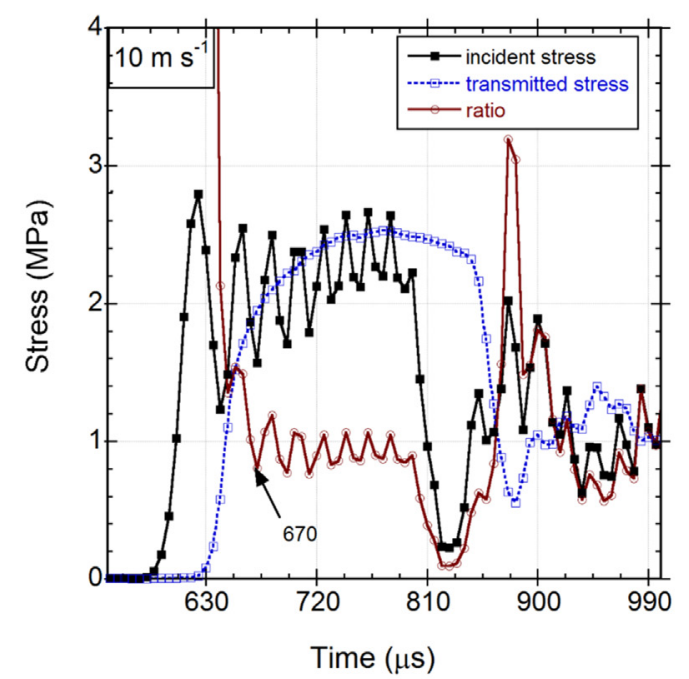

(c)

Fig. 9. (a) The test and two-layer imperfect model SHPB incident and transmitted stresses as function of time and (b) The stress-strain curves of test and perfect and imperfect models at $6 \mathrm{~m} \mathrm{~s}^{-1}$ and (c) The perfect model incident and transmitted stresses and the stress ratio as function of time at $10 \mathrm{~m} \mathrm{~s}^{-1}$. determined time step without mass scaling was multiplied by 10,100 and 1000. It was found numerically that the kinetic energy change was substantially lower than the internal energy change when the mass scaling factor was 1000 . For quasi-static models, the contact between fin layers was defined by ERODING_SINGLE_SURFACE contact algorithm. The full numerical model of the SHPB test and the sample/bar interfaces are shown in Fig. 6(b). The Inconel 718 striker, incident and transmitter bars were meshed with $15 \mathrm{~mm}$ elements. The incident and transmitter bars consisted of 28,980 and 19,180 constant stress solid elements, respectively. The impact velocities in the SHPB models were 6 and $10 \mathrm{~m} \mathrm{~s}^{-1}$, the same as the tests. The full model of direct impact test and the sample/bar interfaces are shown in Fig. 6(c). The Inconel incident bar was modeled using $15 \mathrm{~mm}$ elements, while the striker bar was modeled using $5 \mathrm{~mm}$ elements. The $250 \mathrm{~mm}$-long Inconel, $100 \mathrm{~mm}$ long aluminum and $200 \mathrm{~mm}$-long aluminum and wood striker bars' models consisted of 12,000, 4800 and 10,080 constant stress solid elements, respectively. The impact velocities in the direct impact numerical models were 9, 22, 40, 60, 75 and $90 \mathrm{~m} \mathrm{~s}^{-1}$. The impact velocity was defined to the mass by VELOCITY_GENERATION card in LSDyna. The contact between the bar and specimen was defined by AUTOMATIC_SURFACE_TO SURFACE contact. The contact between the corrugated sample and face sheets was defined by AUTOMATIC_SINGLE_SURFACE contact algorithm.

In the SHPB and direct impact tests, the Inconel 718 incident, transmitter and striker bars were modeled using MAT01_ELASTIC material model with $\mathrm{E}=207 \mathrm{GPa}, \mu=0.33$ and $\rho=7850 \mathrm{~kg} \mathrm{~m}^{-3}$. The aluminum and wood striker bars were modeled using MAT01_ELASTIC material model $\left(\mathrm{E}=71.7 \mathrm{GPa}, \mu=0.33\right.$ and $\rho=2810 \mathrm{~kg} \mathrm{~m}^{-3}$ for aluminum and $\mathrm{E}=2.2 \mathrm{GPa}, \mu=0.33$ and $\rho=725 \mathrm{~kg} \mathrm{~m}^{-3}$ for wood [12]). The static and dynamic friction coefficients were set sequentially to 0.3 and 0.2 in all contact definitions. The numerical stresses on the transmitter and incident bars were calculated at the same location with the strain gages in the tests.

\section{Results and discussions}

\subsection{Quasi-static tests}

The quasi-static $\left(0.0048 \mathrm{~m} \mathrm{~s}^{-1}\right)$ compression stress-strain curves of 4 tests are shown in Fig. 7(a) and composed of linear elastic, plateau and densification regions as similar with those of other metallic cellular structures. The quasi-static initial crushing stress varies between 1.2 and 1.30 MPa with an average of $1.25 \mathrm{MPa}$ and the quasi-static mean stress $\left(\sigma_{m}=\frac{\int \sigma d \varepsilon}{\varepsilon}\right.$ ) between 0.95 and $1.05 \mathrm{MPa}$ (at 0.4 strain) with an average of $0.98 \mathrm{MPa}$ as shown in Fig. 7(a). The densification strain was determined by the intercept method. A tangent line is drawn to the densification part of stress-strain curve and the intercept of this line with the mean crushing stress was taken as the densification strain. The experimental densification strain by this method is 0.67 as seen in Fig. 7(a). The stress-strain and mean stress-strain curve of the perfect model and the stress-strain curve of the test are shown together in Fig. 7(b). Although the perfect model results in nearly a similar mean stress $(0.93 \mathrm{MPa})$ with the test, it shows a higher initial crushing stress, 2.26 MPa. The insertions of two and full imperfect layers reduce the initial crushing stress sequentially to 1.45 and $1.52 \mathrm{MPa}$ without significantly affecting the densification strain (Fig. 7(c)). The imperfect models show somewhat similar mean stresses $(\sim 0.88 \mathrm{MPa}$ at 0.4 strain $)$ with each other and relatively comparable with the test. Finally, all quasi-static models result in similar densification strains, $\sim 0.72$, slightly higher than that of the test (Fig. 7(b)).

The deformation pictures of the quasi-static test and models until about $0,0.2,0.4,0.6$ and 0.8 strains are shown in Fig. 8(a-c). The collapse in the test starts in the 9th layer, then proceeds with the crushing of the 5th and 6th layer at 0.2 strain (Fig. 8(a)). The crushing continues discretely at the top and bottom layers at 0.4 and 0.6 strain. 

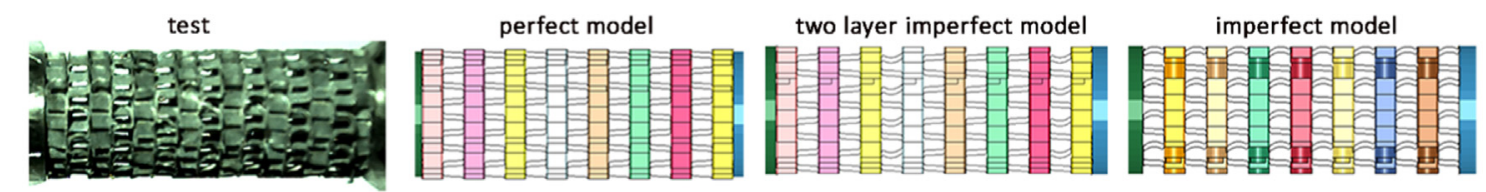

1

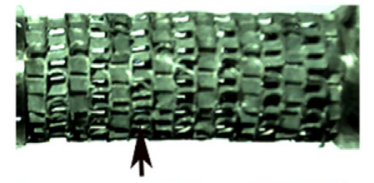

2
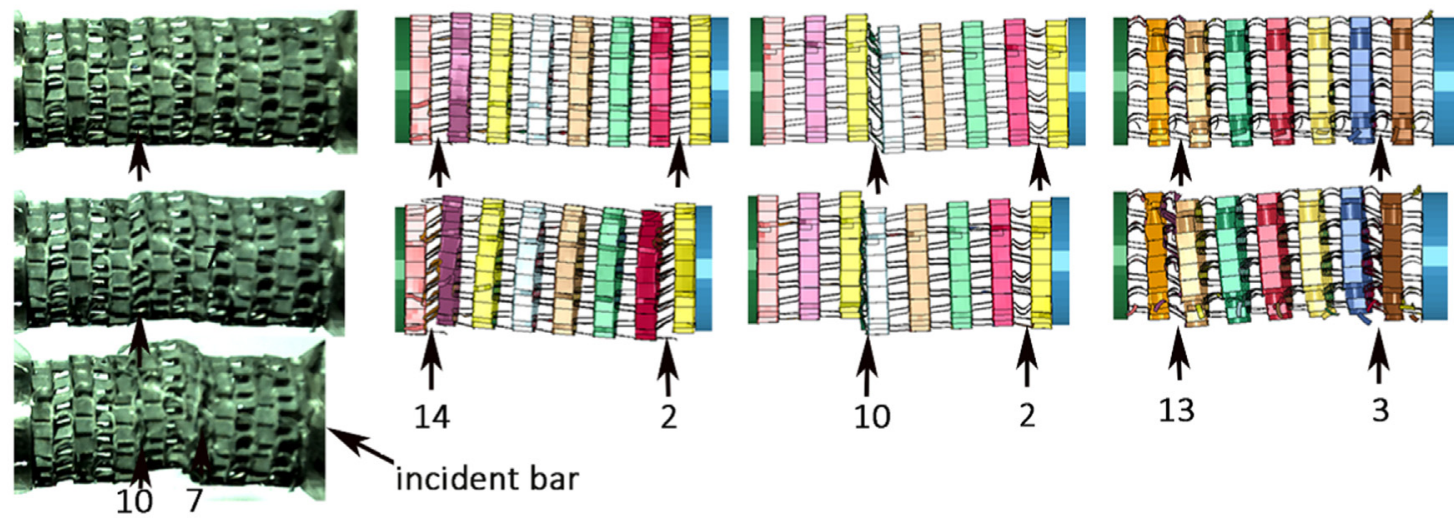

(a)
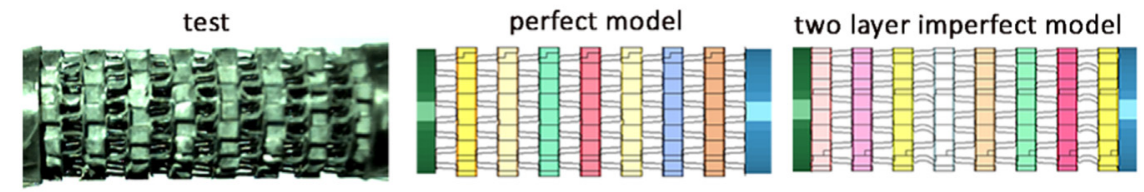

imperfect model
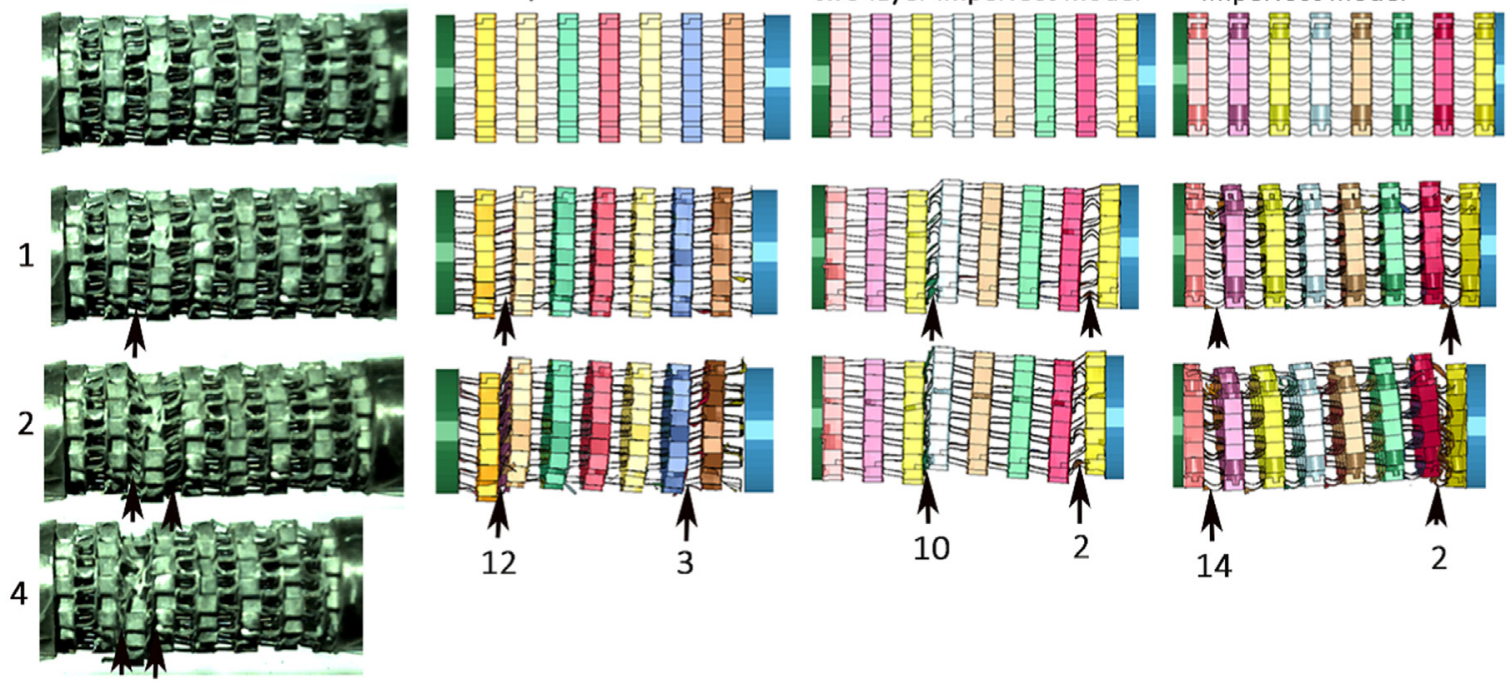

1210

(b)

Fig. 10. Deformation pictures of SHPB tests and models (numbers shows the reloading) at (a) 6 and (b) $10 \mathrm{~m} \mathrm{~s}^{-1}$.

The discrete layer crushing causes the sample to bend after 0.2 strain. The layer collapse in the perfect model initiates in the layers near the ends of the sample (14th and 2nd layer) at 0.2 strain and continues sequentially with the crushing of the mid-section layers at increasing strains as shown with the arrows in Fig. 8(b)). Since the layer crushing is sequential, no sample bending is detected in the perfect model. The initial crushing in the two-layer imperfect model starts in the imperfect 10th layer followed by the crushing of the 8th, imperfect 2nd and 4th layer as shown with the arrows in Fig. 8(c)). As with the test, the sample in this model is bent after about 0.2 strain. Simulation was also implement with the one layer imperfect model (10th layer), but no bending of the sample was detected. The layer collapse and the deformation of the sample in the fully imperfect model (not shown here) were also very similar to those of the perfect model: the layers near the sample's ends collapsed initially and no global bending of the sample was observed.

\subsection{SHPB tests}

Fig. 9(a) shows the incident stress-time and transmitted stress-time histories of the test and imperfect model at $6 \mathrm{~m} \mathrm{~s}^{-1}$. The experimental and numerical model incident and reflected stresses marked sequentially as number 1 and 2 in Fig. 9(a) are very similar. The oscillations in the transmitted stress of the test marked as number 3 in Fig. 9(a) are due to the noise of the data acquisition system measuring relatively low strains. However, the transmitted stress variations in the test are detectable and comparable with the numerical stresses. Since the sample is not completely separated from the bars during a test, the returning compressive wave from the end of the incident bar reloads the sample every $\sim 1200 \mu$ s for a duration of $325 \mu$ following an elastic relaxation after each repeated loading (the difference between the starting times of the first and second incident waves is $1200 \mu$ s in Fig. 9(a)). Each dotted rectangle in Fig. 9(a) represents the time duration of the sample loading. Within the time scale of Fig. 9(a), the sample is almost loaded two-time. As the strain gages measure both incoming and going waves, 


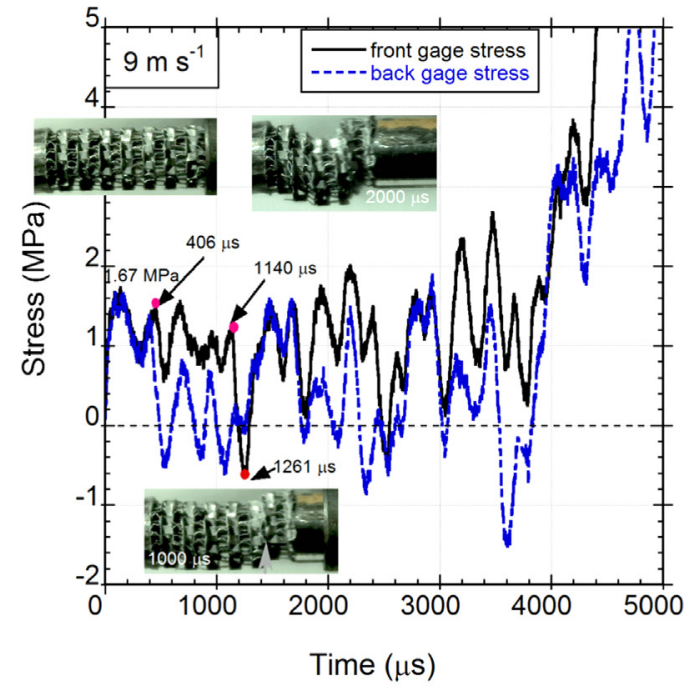

(a)

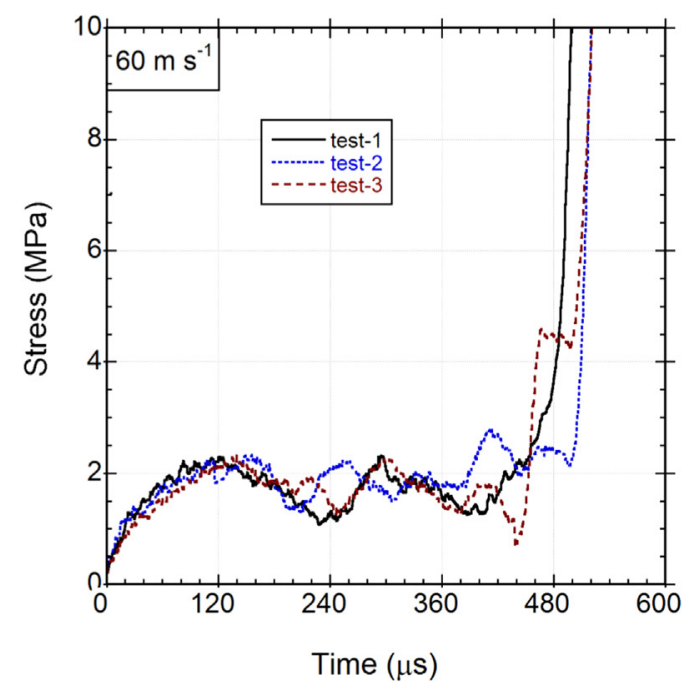

(b)

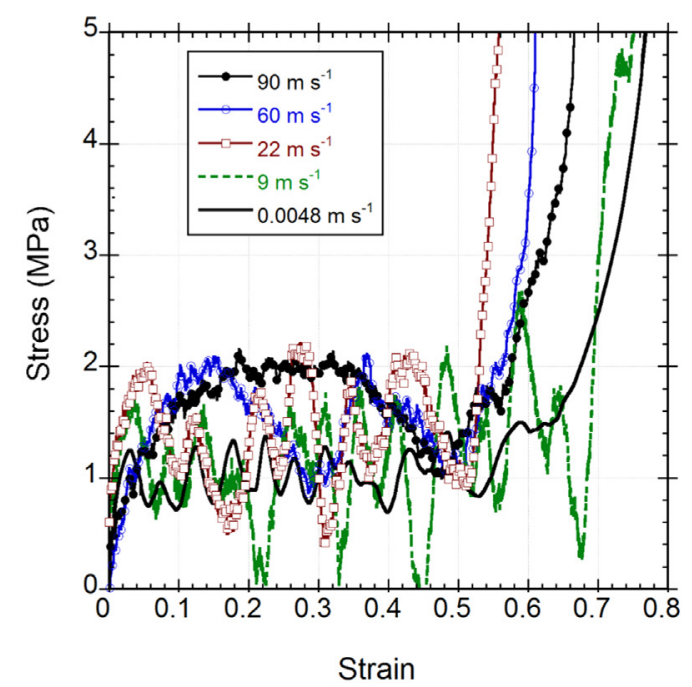

(c)

Fig. 11. (a) Front and back strain gage stress-time curves at $9 \mathrm{~m} \mathrm{~s}^{-1}$ and (b) Front strain gage stress-strain curves of three tests at $60 \mathrm{~m} \mathrm{~s}^{-1}$ and (c) Stressstrain curves at different velocities. the separation of these waves on the sample was rather difficult; therefore, only the first loading in the tests was used to determine the stress-strain and stress-time profiles of the samples. Note that there is a relatively small time shift between the test and model waves in Fig. 9(a). The model stresses were determined from an element at a distance from the bars/sample interfaces, nearly the same as the test, but the sizes of the element and strain gages were quite different, $15 \mathrm{~mm}$ and $\sim 5 \mathrm{~mm}$, respectively. This naturally causes a time shift between the test and model stress waves. Furthermore, the sample geometry and surface flatness are perfect in the model, while they show deviations from the ideality in the tests.

The numerical and representative test stress-strain curves at $6 \mathrm{~m} \mathrm{~s}^{-1}$ are shown in Fig. 9(b). The numerical sample stress in the same figure was determined at the transmitter bar/sample interface. The numerical strain was calculated from the displacement difference between the incident bar/sample and transmitter bar/sample contacts in order to determine the stress-strain curve in the second and third loadings. The maximum stresses are sequentially $1.49,2.35,1.52$ and $1.52 \mathrm{MPa}$ at $6 \mathrm{~m} \mathrm{~s}^{-1}$ for the test and perfect, two-layer imperfect and fully imperfect model, respectively. These values were sequentially 1.65, 2.48, 165 and $1.65 \mathrm{MPa}$ at $10 \mathrm{~m} \mathrm{~s}^{-1}$. The two-layer imperfect and fully imperfect model are noted to show similar initial peak stresses with the test at 6 and $10 \mathrm{~m} \mathrm{~s}^{-1}$. As seen in Fig. 9(b), the initial crushing stress values of the SHPB test and models are higher than that of the quasi-static test. Fig. 9(c) shows the incident and transmitter bar contact stresses of the perfect model and the ratio of the incident bar stress to the transmitter bar stress as function of time at $10 \mathrm{~m} \mathrm{~s}^{-1}$. The difference between the start-time of the incident and the transmitted stress $(\sim 40 \mu \mathrm{s})$ in Fig. 9(c) simple shows the wave transit time of the sample. The initially high ratio of the incident stress to the transmitted stress approaches one at $670 \mu \mathrm{s}$. A stress ratio of one indicates the stress equilibrium in the sample [39]. The similar stress equilibrium was also found in the twolayer imperfect and fully imperfect models. The average strain rates of the tests and models were also similar and sequentially $\sim 175$ and $\sim 200 \mathrm{~s}^{-1}$ at 6 and $10 \mathrm{~m} \mathrm{~s}^{-1}$, respectively.

The deformation pictures of the tests and models, sequentially at the end of the third- and second-loading at 6 and $10 \mathrm{~m} \mathrm{~s}^{-1}$ are shown in Fig. 10(a) and (b), respectively. The strain localization in the tests, at both velocities, starts at the mid-section layers, sequentially in the 10th and 12th layer, and progresses non-sequentially with the crushing of the 7th and 10th layer as shown by the arrows in Fig. 10(a) and (b). In the perfect and fully imperfect model, the strain localization at both velocities starts in the layers near the incident and transmitter bars and progresses non-sequentially (Fig. 10(a) and (b)). In the two-layer imperfect model, the layer collapse is seen to start in the 10th and 2nd imperfect layer at both velocities.

\subsection{Direct impact tests}

Fig. 11(a) shows the front and back strain gage stress-time history of the direct impact test at $9 \mathrm{~m} \mathrm{~s}^{-1}$. Since the front gage is $300 \mathrm{~mm}$ and the back strain gage $1810 \mathrm{~mm}$ away from the incident bar/sample interface, the front gage stress and the back gage stress were sequentially shifted by 60.8 and $367 \mu \mathrm{s}\left(\mathrm{c}=4930 \mathrm{~m} \mathrm{~s}^{-1}\right)$ on the time axis for comparison. The reflected tensile wave from the distal end of the incident bar reaches the back and front strain gage at 405.6 and $1140 \mu$ s, respectively. This reflected tensile wave returns back largely as the compressive wave to the front gage of the incident bar at $1261 \mu$ s due to the relatively low mechanical impedance of the sample. These calculated times based on the Inconel bar wave velocity and distances between strain gages and the bar ends perfectly match to the experimentally determined times as shown by arrows in Fig. 11(a). As is seen in the same figure, the front and back strain gage read the same initial peak stress of $1.67 \mathrm{MPa}$ at $9 \mathrm{~m} \mathrm{~s}^{-1}$. Since the front strain gage reading is affected by the returned tensile wave at a longer time, $1140 \mu \mathrm{s}$, the sample stresses were determined using the front strain gage reading. 
(a)

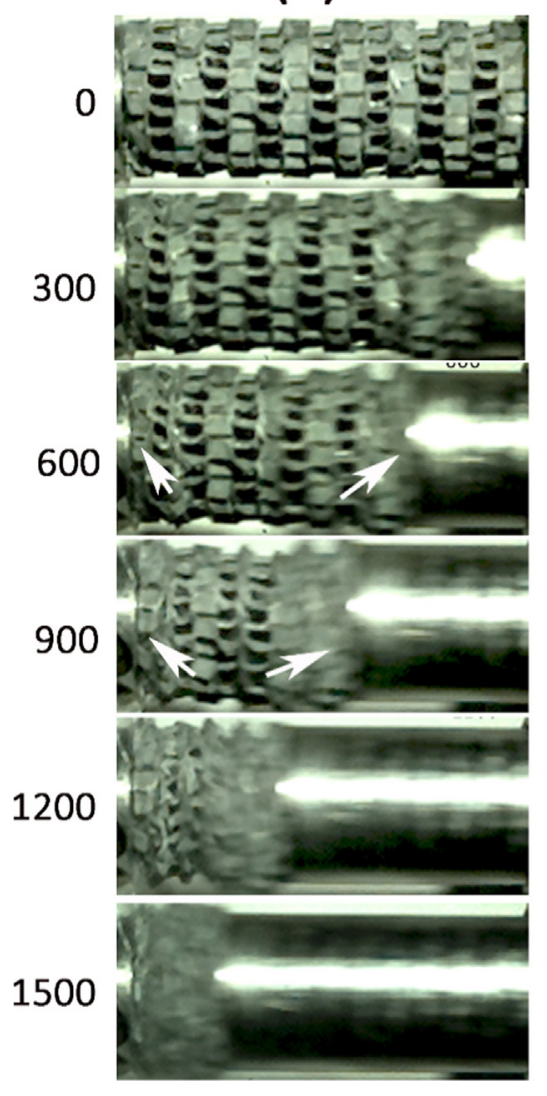

(b)

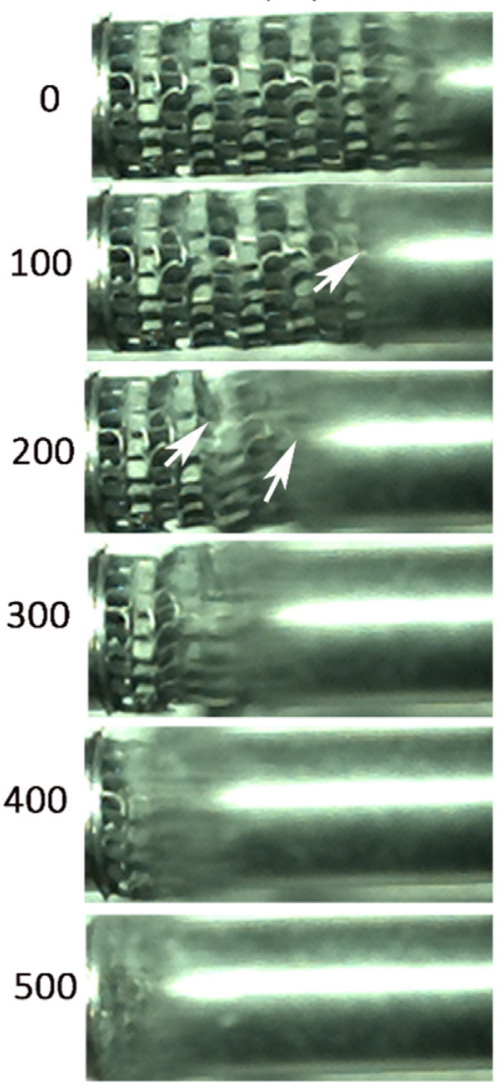

(c)
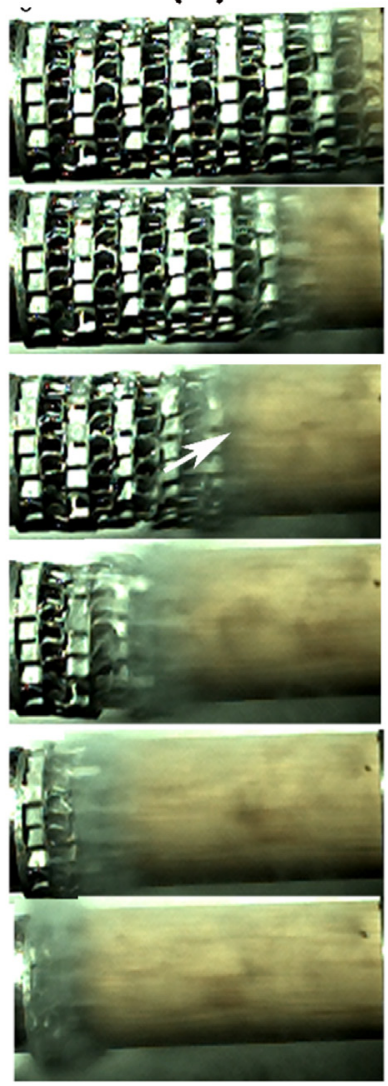

Fig. 12. Deformation pictures of the direct impact tested samples at (a) 22, (b) 60 and (c) $90 \mathrm{~m} \mathrm{~s}^{-1}$.

The deformation pictures of the sample tested at $9 \mathrm{~m} \mathrm{~s}^{-1}$ at 1000 and $2000 \mu$ s are shown in the inset of Fig. 11(a). As with the quasi-static and SHPB test, the layer crushing at this velocity starts in the mid-section layers and progresses non-sequentially, leading to the global bending of the sample. Fig. 11(b) shows the front gage stress-time curves of three direct impact tests performed at $60 \mathrm{~m} \mathrm{~s}^{-1}$. The stresses in this figure are seen repeatable with an average initial crushing stress of $\sim 2 \mathrm{MPa}$. The front gage stress-strain curves of the direct impact tests at different velocities are shown together with that of the quasi-static test in Fig. 11(c). The initial crushing stress seen in the same figure increases from 1.25 MPa at quasi-static velocity to $\sim 2 \mathrm{MPa}$ at $22 \mathrm{~m} \mathrm{~s}^{-1}$; thereafter, the initial crushing stress remains almost constant until $90 \mathrm{~m} \mathrm{~s}^{-1}$.

The deformation pictures of the direct impact tested samples at 22, 60 and $90 \mathrm{~m} \mathrm{~s}^{-1}$ are shown in Fig. 12(a-c), respectively. The numbers in the same figures indicate the time-elapsed after the impact in $\mu$. No global bending of the sample is noted to be seen at 22, 60 and $90 \mathrm{~m} \mathrm{~s}^{-1}$ tests. The layer crushing at $22 \mathrm{~m} \mathrm{~s}^{-1}$ initiates at both the impact and distal end, while the layer crushing dominantly occurs at the impact end at 60 and $90 \mathrm{~m} \mathrm{~s}^{-1}$ as shown by the arrows in Fig. 12(a-c). The layer crushing at $60 \mathrm{~m} \mathrm{~s}^{-1}$ is sequential until about $200 \mu \mathrm{s}$; then it switches to non-sequential or diffusive mode (Fig. 12(b)). The layer crushing at $90 \mathrm{~m} \mathrm{~s}^{-1}$ is nearly sequential, showing a shock deformation (Fig. 12(c)). Fig. 13(a-d) show numerical deformation pictures of the samples at 22,60, 75 and $90 \mathrm{~m} \mathrm{~s}^{-1}$, respectively. Again, the numbers in these figures show the time-elapsed after the impact. Numerically, the layer crushing at $22 \mathrm{~m} \mathrm{~s}^{-1}$ starts at both ends of the sample in the perfect model and proceeds non-sequentially (Fig. 13(a)). The layer crushing in the two-layer imperfect and fully imperfect model starts near the impact end and/or at the midsection layers, but the layer crushing proceeds non-sequentially again (Fig. 13(a)). The layer crushing at 60 and $75 \mathrm{~m} \mathrm{~s}^{-1}$ starts from the impact end in all models.
But, the crushing becomes non-sequential after $200 \mu$ s in the perfect model and after $100 \mu$ s in the two-layer imperfect model. The layer crushing in the fully imperfect model is sequential but relatively diffusive as seen in Fig. 13(b) and (c). The layer crushing in the perfect and two-layer imperfect models at $90 \mathrm{~m} \mathrm{~s}^{-1}$ starts from the impact end, but it progresses non-sequentially at the later stages of the deformation as seen in Fig. 13(d). The layer crushing sequence of the fully imperfect model shown in the same figure is very much similar with that of the test: the layer crushing progresses from the impact end to the distal end nearly in a sequential mode.

\subsection{Layer strains and distal end and impact end stresses}

The layer strain-time and nominal strain-time histories of the twolayer imperfect model at $22 \mathrm{~m} \mathrm{~s}^{-1}$ and $90 \mathrm{~m} \mathrm{~s}^{-1}$ and the fully imperfect model at 60 and $75 \mathrm{~m} \mathrm{~s}^{-1}$ are shown in Fig. 14(a-d), respectively. The layer strain-time history of the two-layer imperfect model at $22 \mathrm{~m} \mathrm{~s}^{-1}$ clearly indicates a non-sequential crushing behavior (Fig. 14(a)). The strains of the initially crushed layers are also noted to be lower than the densification strain and reach the densification strains at the later stages of the deformation (Fig. 14(a)). The layer strain-time history of the fully imperfect model at $22 \mathrm{~m} \mathrm{~s}^{-1}$ was also similar to that of the two-layer imperfect model with a non-sequential crushing behavior. The layer strain-time history of the two-layer imperfect model at $90 \mathrm{~m} \mathrm{~s}^{-1}$ is sequential until about the crushing of the 5th layer ( $200 \mu$ s); thereafter, the layer crushing becomes non-sequential as seen in Fig. 14(b). The layer strain-time history of the fully imperfect model at $60 \mathrm{~m} \mathrm{~s}^{-1}$ shows non sequential crushing after the crushing of the 9th layer (shown by an arrow in Fig. 14(c)) after $\sim 400 \mu \mathrm{s}$, while this non sequential layer crushing is not easily detectible in the deformation micrograph in Fig. 13(c). As opposite, thoroughly a sequential layer 


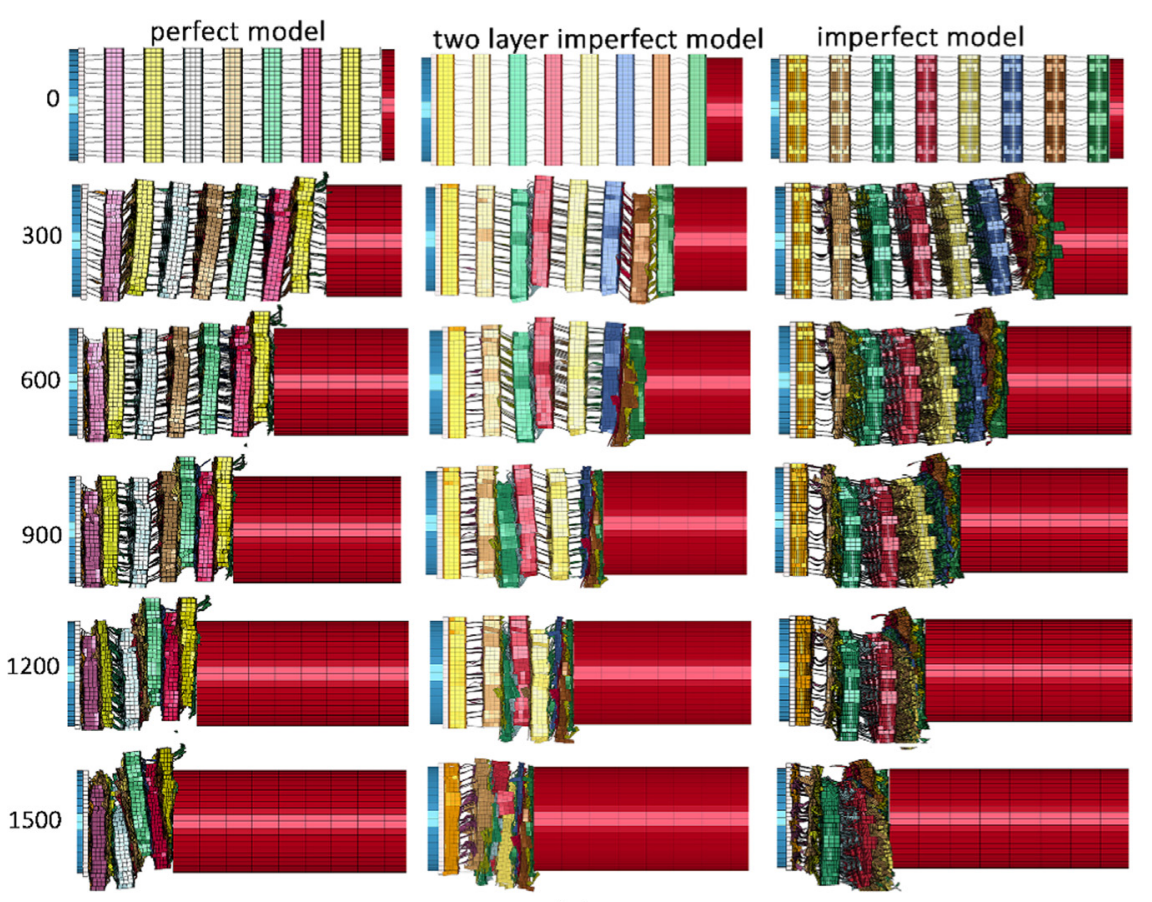

(a)

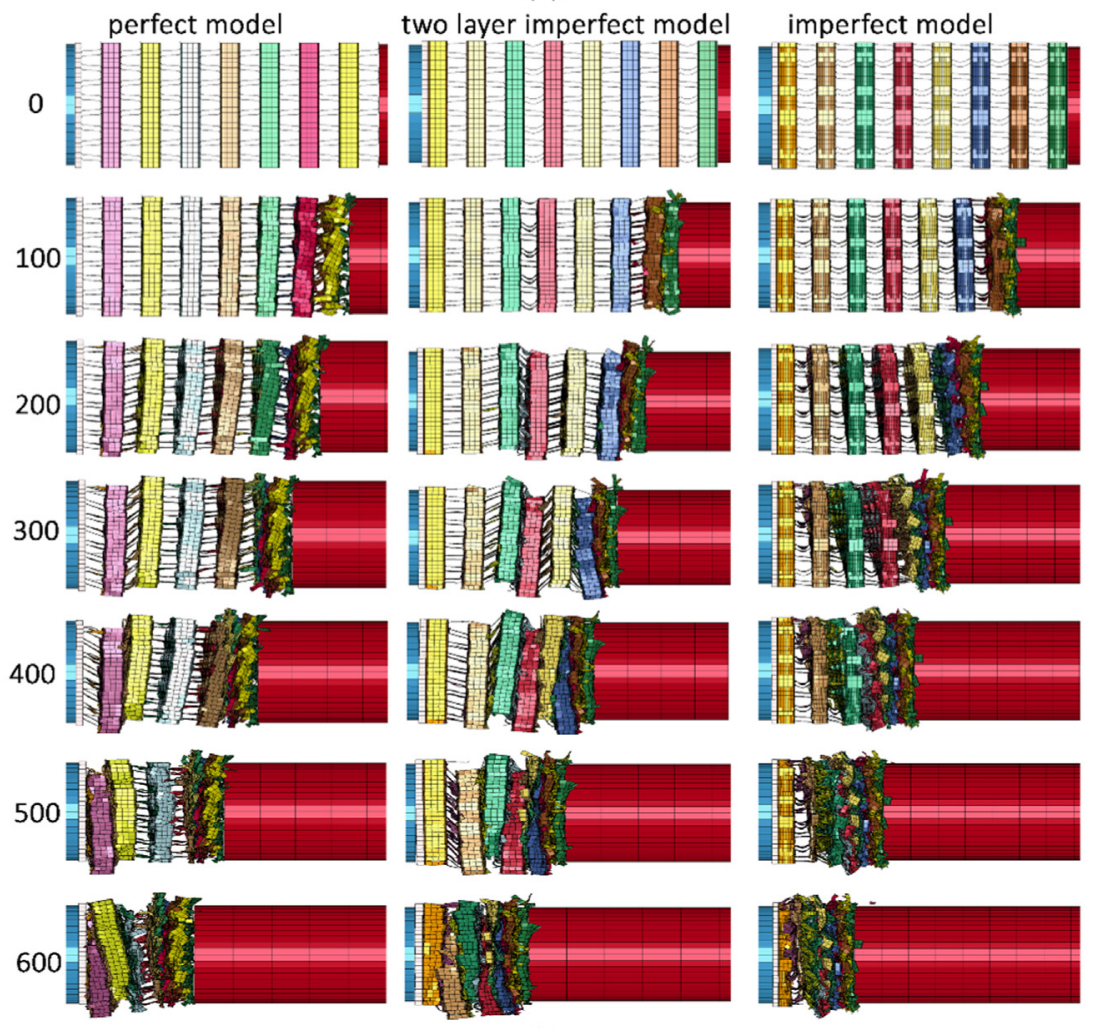

(b)

Fig. 13. Deformation pictures of the direct impact test models at (a) 22, (b) 60, (c) 75 and (d) $90 \mathrm{~m} \mathrm{~s}^{-1}$.

crushing is seen at $75 \mathrm{~m} \mathrm{~s}^{-1}$ (Fig. 14(d)) and also at $90 \mathrm{~m} \mathrm{~s}^{-1}$ (not shown here). This is also well accord with the experimentally observed sequential layer crushing at $90 \mathrm{~m} \mathrm{~s}^{-1}$ (Fig. 12(c)). By measuring the peak strain values of the first three crushed layers in Fig. 14(c) and (d), the numerical densification strains of 0.67 and 0.7 are determined for 60 and $75 \mathrm{~m} \mathrm{~s}^{-1}$, respectively.

Fig. 15(a) and (b) show sequentially the incident bar (distal end) and striker bar (impact end) contact stresses-strain curves of the two- layer imperfect model at increasing velocities. At all velocities, the incident bar contact stress-strain curves exhibit the stress oscillations, the same as the quasi-static tests (Fig. 15(a)). Although, the direct impact incident bar contact stresses are slightly higher than those of the quasistatic especially in the initial region of the curves, they are almost equal to each other at and above $22 \mathrm{~m} \mathrm{~s}^{-1}$ until about 0.5 strain. The striker bar contact stresses increase with increasing velocity initially, for example until about 0.3 strain at $90 \mathrm{~m} \mathrm{~s}^{-1}$; thereafter, the deformation 


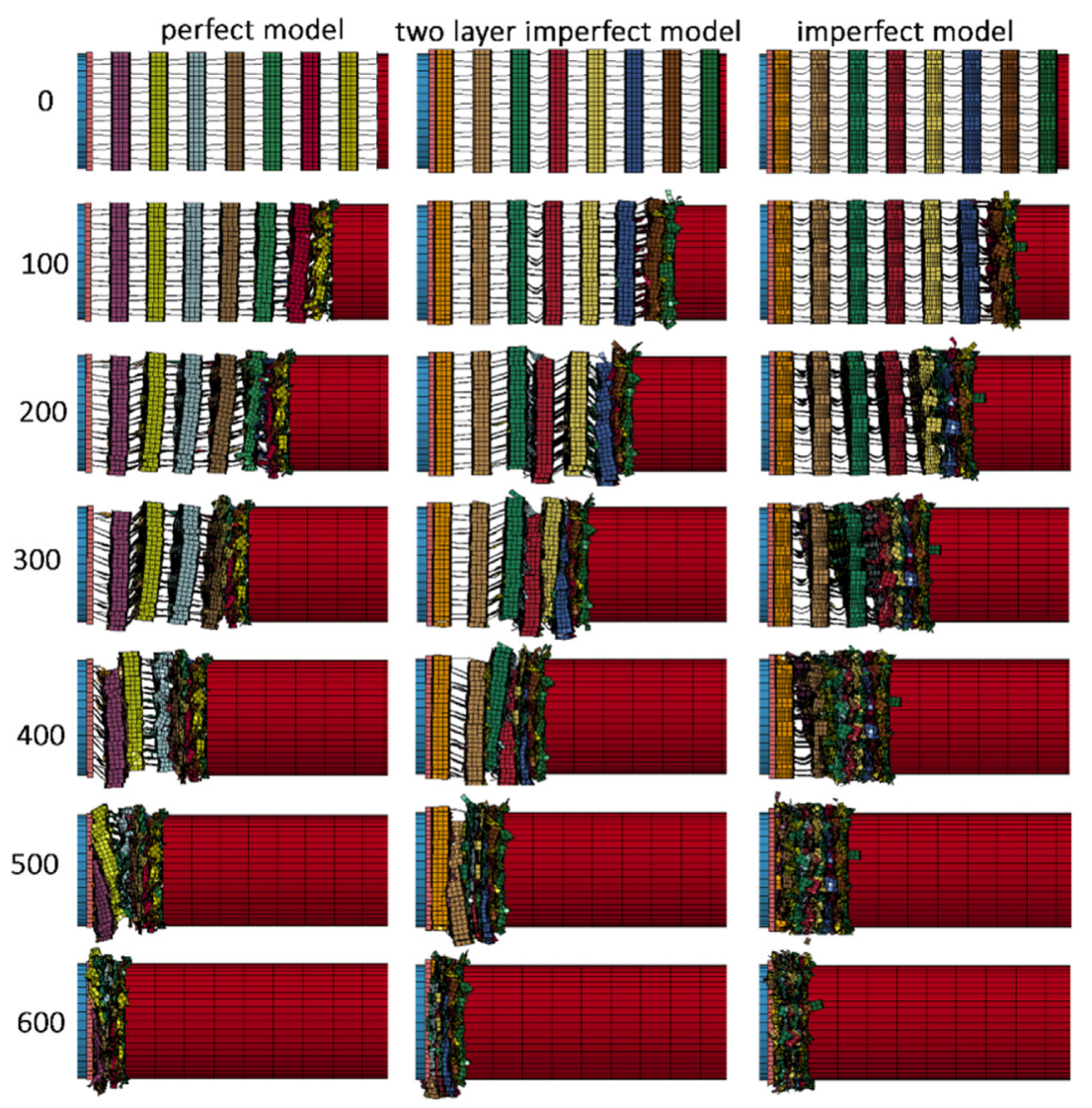

(c)
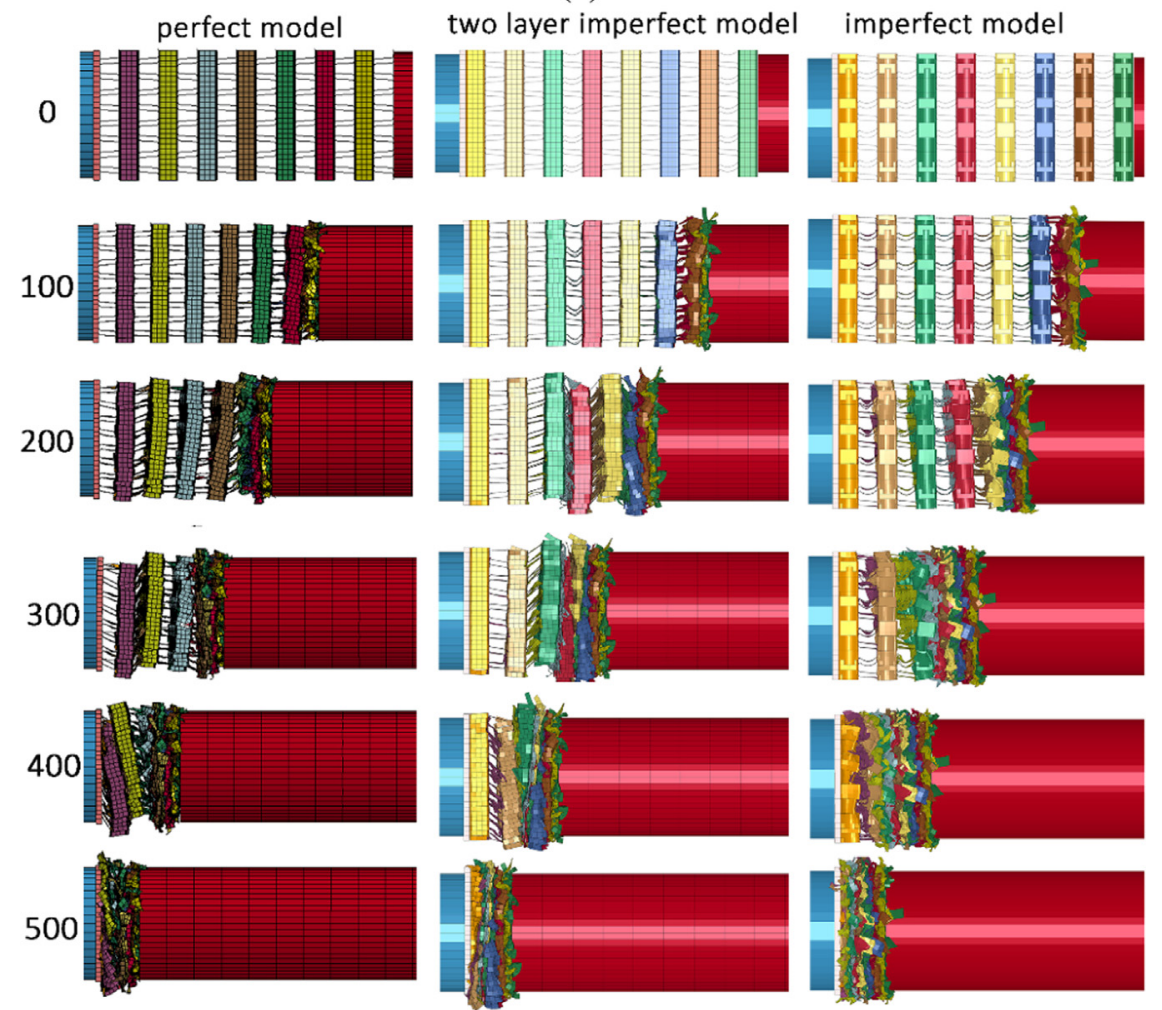

(d)

Fig. 13. (continued) 


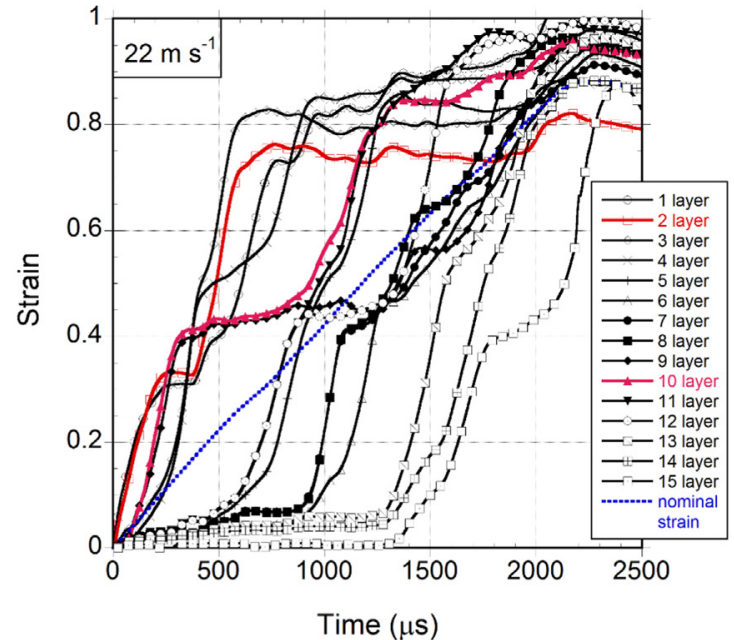

(a)

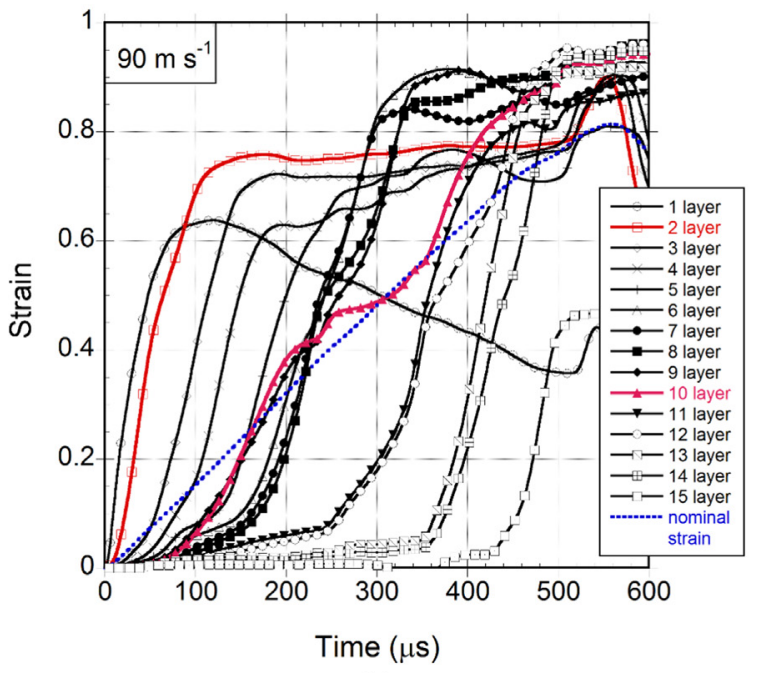

(b)

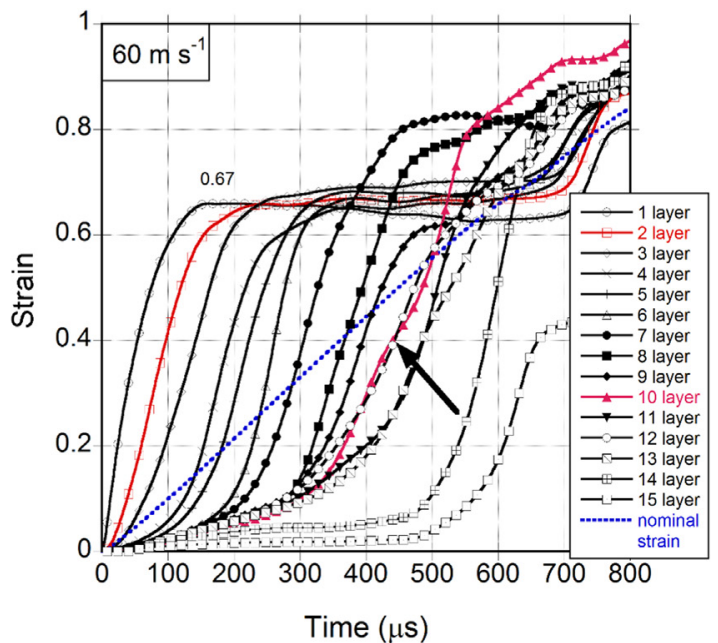

(c)

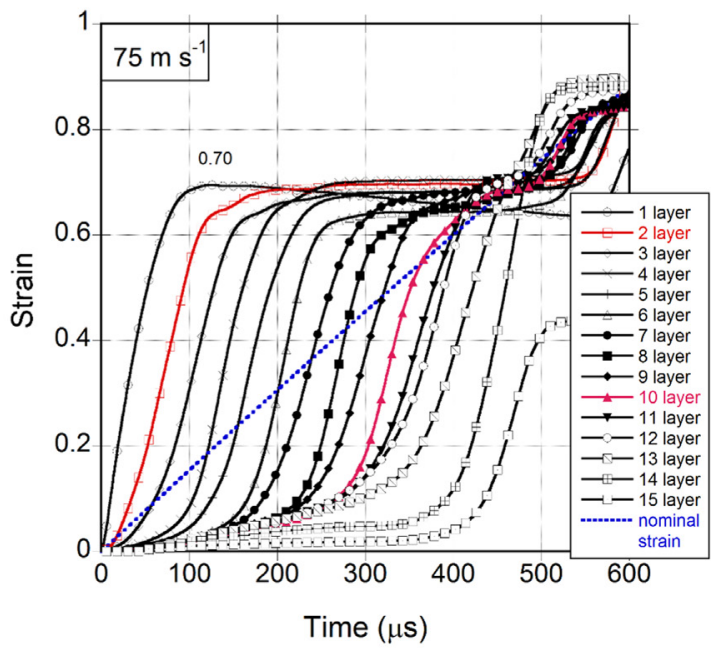

(d)

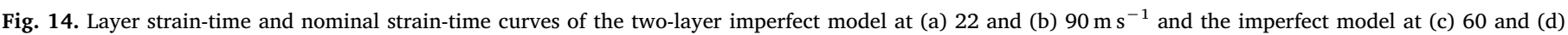
$75 \mathrm{~m} \mathrm{~s}^{-1}$.

switches nearly into the quasi-static mode as seen in Fig. 15(b). This is reflected as a stress-drop after 0.3 strain in the stress-strain curve. As opposite to the two-layer imperfect model, the fully imperfect model incident bar contact stresses at 60 and $90 \mathrm{~m} \mathrm{~s}^{-1}$ show no stress oscillations and are almost saturated at about $2 \mathrm{MPa}$ as shown in Fig. 15(c). This further confirms a sequential layer crushing at $90 \mathrm{~m} \mathrm{~s}^{-1}$ and is in accord with the experimentally determined nearly a constant distal end stress $(\sim 2 \mathrm{MPa})$ at $90 \mathrm{~m} \mathrm{~s}^{-1}$ in Fig. 11(c). The striker bar contact stresses of 60,75 and $90 \mathrm{~m} \mathrm{~s}^{-1}$ are also higher than the stresses of quasi-static velocity at all strain values as seen in Fig. 15(d). For comparison purposes, the impact end stresses of the two-layer imperfect and fully imperfect model are determined. The stresses corresponding to 0.05 strain are taken as the impact end stress, except the stress of the imperfect model at $90 \mathrm{~m} \mathrm{~s}^{-1}$. At this velocity, the stress is determined at 0.1 strain since there is a big stress-drop at 0.05 strain, not representing the global stress behavior of the model. The determined impact end stresses are shown by the dotted lines in Fig. 15(b) and (d).

\subsection{Effect of velocity on deformation modes}

The investigated corrugated structure deforms by forming discrete crush bands at $0.0048 \mathrm{~m} \mathrm{~s}^{-1}$. The crush band initiates at the weakest fin layer and progresses non-sequentially to the uncrushed layers/parts. Above deformation mode is also seen in the SHPB tests $\left(6\right.$ and $\left.10 \mathrm{~m} \mathrm{~s}^{-1}\right)$ and in the direct impact tests $\left(9 \mathrm{~m} \mathrm{~s}^{-1}\right)$. Since the numerically calculated impact end and distal end stresses are nearly equal (Fig. 9(b)), this deformation mode is therefore referred as to "quasi-static homogenous mode" [9]. The similar homogenous deformation mode was previously identified in regular and irregular honeycomb structures as X-shape shear bands [3], Voronoi honeycombs [6] and corrugated structures [26]. As the layer crushing localizes in the mid-sections of the cylindrical test sample in the homogenous deformation mode, the sample bending occurs during a test (Figs. 8(a), 10(a) and 11(a)). In order to determine the effect of the diameter of the sample on the bending deformation, the samples in $40 \mathrm{~mm}$-diameter and $48 \mathrm{~mm}$-height were quasi-statically compression tested and the same global bending of the sample was also observed. A similar sample bending is found in the two-layer imperfect model (Fig. 8(c)), while no specimen bending is seen in the perfect and fully imperfect model (Fig. 8(b)). The increase of the initial stress between 0.0048 and $22 \mathrm{~m} \mathrm{~s}^{-1}$ are ascribed to the micro inertial effects. The energy absorbing structures are classified as Type I and Type II [40]. Type I structures show a flat-topped load-displacement curve, while Type II structures exhibit an initial peak-load followed by a sharp decline. The increased deformation forces at increasing deformation rates in the compression of aluminum honeycomb structures through out of plane [41], metallic columnar structures [42], aluminum foams [43] and balsa wood in the axial direction [12,44] were reported due to the micro inertial effects. The corrugated core 


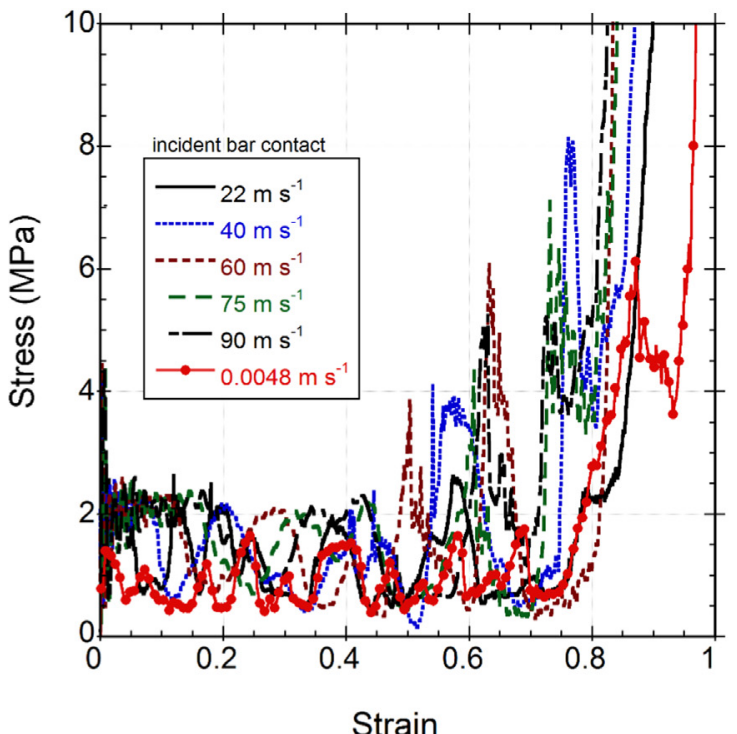

(a)

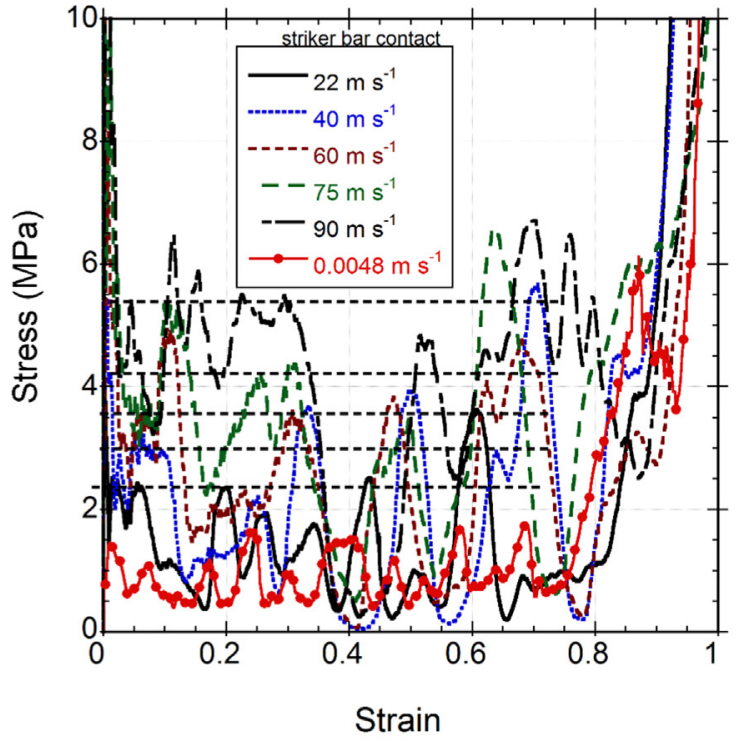

(b)

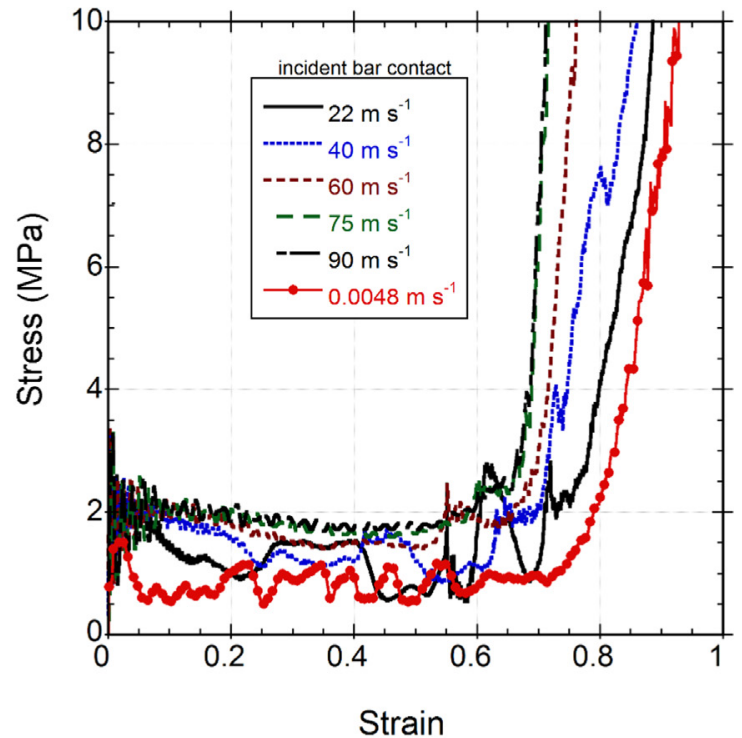

(c)

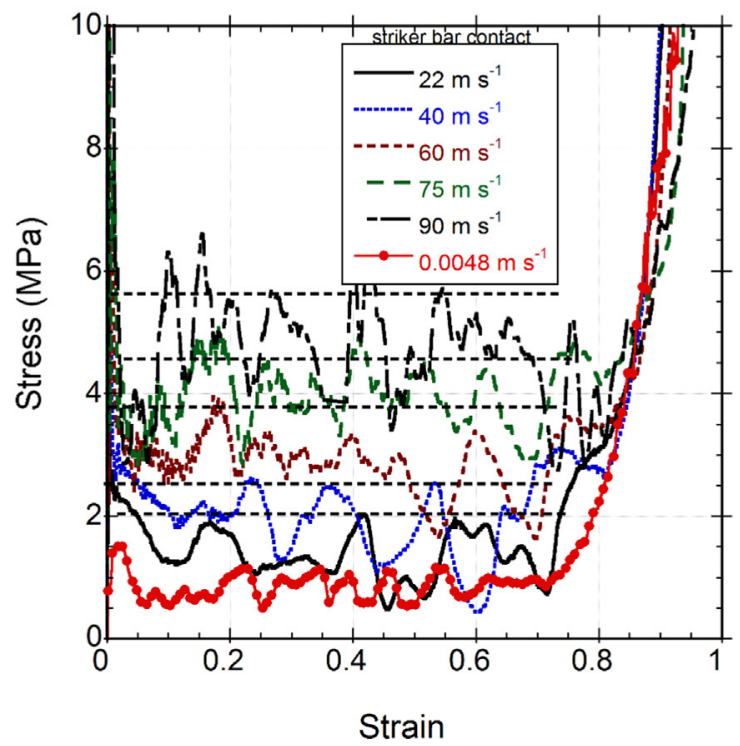

(d)

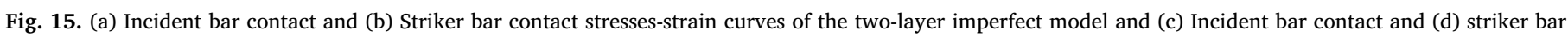
contact stresses-strain curves of the fully imperfect model at $22-90 \mathrm{~m} \mathrm{~s}^{-1}$ (the dotted lines show the impact end stress).

Table 1

The incident bar/sample (distal end) and striker bar/sample (impact end) stresses of the tests and perfect, two-layer imperfect and fully imperfect layer models.

\begin{tabular}{|c|c|c|c|c|c|c|c|c|}
\hline \multirow[t]{2}{*}{ Velocity $\left(\mathrm{m} \mathrm{s}^{-1}\right)$} & \multicolumn{2}{|l|}{ Test } & \multicolumn{2}{|l|}{ Perfect } & \multicolumn{2}{|c|}{ Two-layer imperfect } & \multicolumn{2}{|c|}{ Fully imperfect } \\
\hline & $\begin{array}{l}\text { Incident bar/ } \\
\text { sample stress } \\
\text { (MPa) }\end{array}$ & $\begin{array}{l}\text { Striker bar/ } \\
\text { sample stress } \\
(\mathrm{MPa})\end{array}$ & $\begin{array}{l}\text { Incident bar/ } \\
\text { sample stress } \\
(\mathrm{MPa})\end{array}$ & $\begin{array}{l}\text { Striker bar/ } \\
\text { sample stress } \\
(\mathrm{MPa})\end{array}$ & $\begin{array}{l}\text { Incident bar/ } \\
\text { sample stress } \\
(\mathrm{MPa})\end{array}$ & $\begin{array}{l}\text { Striker bar/ } \\
\text { sample stress } \\
(\mathrm{MPa})\end{array}$ & $\begin{array}{l}\text { Incident bar/ } \\
\text { sample stress } \\
\text { (MPa) }\end{array}$ & $\begin{array}{l}\text { Striker bar/ } \\
\text { sample stress } \\
(\mathrm{MPa})\end{array}$ \\
\hline $4.8 \times 10^{-3}$ & 1.25 & 1.25 & 2.26 & 2.26 & 1.45 & 1.45 & 1.52 & 1.52 \\
\hline 6 & 1.49 & 1.49 & 2.35 & 2.35 & 1.52 & 1.52 & 1.58 & 1.58 \\
\hline 10 & 1.65 & 1.65 & 2.48 & 2.48 & 1.65 & 1.65 & 1.65 & 1.65 \\
\hline 22 & 1.92 & & & & 1.97 & 2.3 & 2 & 2.2 \\
\hline 40 & 1.98 & & & & 2.06 & 3 & 2.08 & 2.55 \\
\hline 60 & 2.1 & & 3.0 & 3.65 & 2.17 & 3.55 & 2.1 & 3.8 \\
\hline 75 & - & & 3.1 & 4.40 & 2.14 & 4.30 & 2.1 & 4.6 \\
\hline 90 & 2.13 & & 3.12 & 5.5 & 2.2 & 5.4 & 2.14 & 5.65 \\
\hline
\end{tabular}




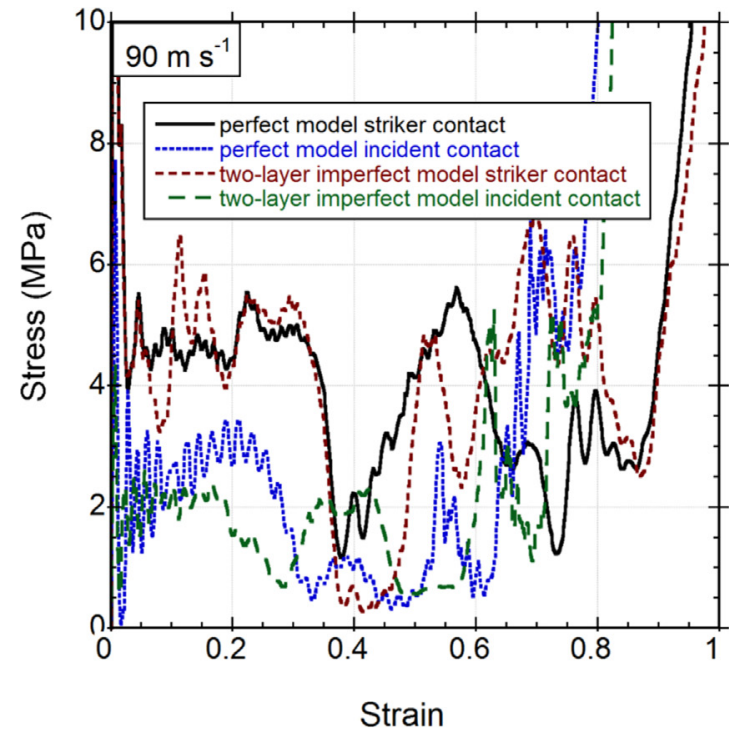

(a)

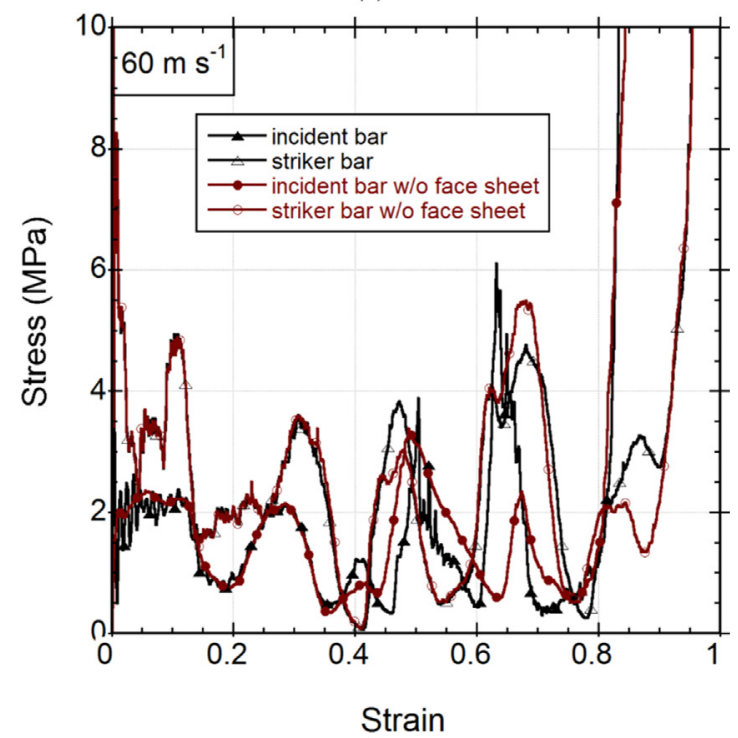

(b)

Fig. 16. Incident bar contact and striker bar contact stresses-strain curves of the two-layer imperfect model and perfect model at $90 \mathrm{~m} \mathrm{~s}^{-1}$ and (b) Two-layer imperfect model with and without face sheet at $60 \mathrm{~m} \mathrm{~s}^{-1}$.

tested in present study also shows micro inertia-sensitive Type II behavior. The propagation of the plastic wave at high strain rates suppresses the more compliant bending modes and hence increases the initial crushing stress [45]. Since the layer crushing is noted to be more concentrated at the impact end than the distal end between 22 and $60 \mathrm{~m} \mathrm{~s}^{-1}$ (Fig. 12(a) and (b)); the deformation between these velocities is considered as the "transition mode". The layer strains in this mode are wide/diffusive rather than narrow/localized. The crush band strains are also below the densification strain [9]. A shock mode appears when the velocity is at $90 \mathrm{~m} \mathrm{~s}^{-1}$. In this mode, the layers crushes sequentially, starting from the impact end and progressing to the distal end. The layer strains in this mode reach the densification strain.

The incident bar/sample (distal end) and striker bar/sample (impact end) stresses of the tests and perfect, two-layer imperfect and fully imperfect models are tabulated in Table 1 at increasing impact velocities. The incident bar/sample contact stresses are well predicted by the two-layer and fully imperfect model at all velocities, while the deformation modes of the tests are well accord with the two-layer

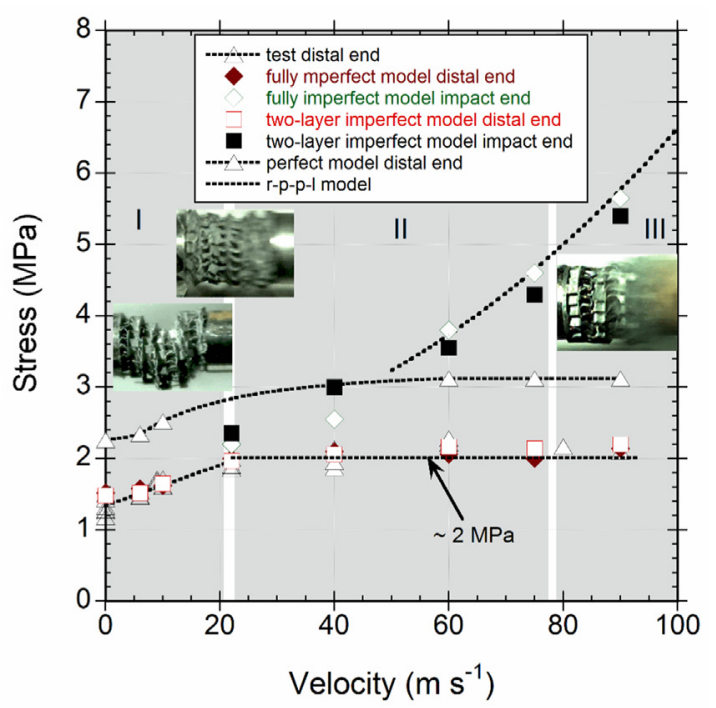

(a)

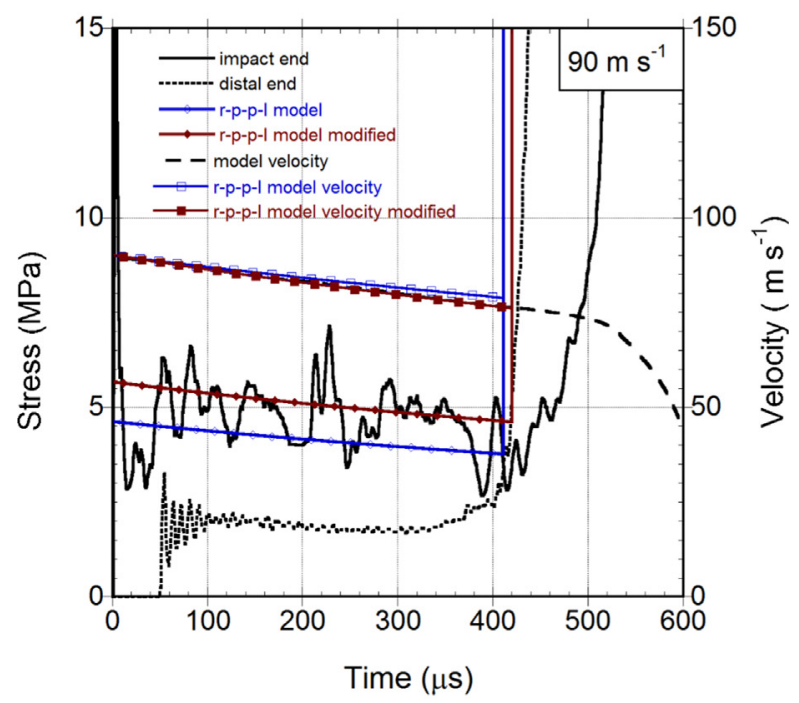

(b)

Fig. 17. (a) The variation of distal and impact end stresses with the velocity and (b) The fully imperfect model distal end and impact end stresses and velocitytime curves with the r-p-p-l model stress-time and velocity-time curves.

imperfect model from quasi-static to $60 \mathrm{~m} \mathrm{~s}^{-1}$. However, the mode of the test at the highest velocity $\left(90 \mathrm{~m} \mathrm{~s}^{-1}\right)$, the shock mode, is well predicted by the fully imperfect model.

\subsection{Effect of imperfection and face sheet}

The effect of imperfect layers on the contact stresses is shown in Fig. 16(a) at $90 \mathrm{~m} \mathrm{~s}^{-1}$. Although, the imperfect layers do not significantly affect the impact end stresses of the two-layer and fully imperfect models, they result in noticeable reductions in the distal end initial crushing stresses of the imperfect models as compared with the distal end stress of the perfect model. The similar imperfection insensitive impact end stresses were reported previously $[26,46]$. In order to see the effect of front-face sheet layer on the contact stresses, the two-layer imperfect model was also implemented without face sheet at $60 \mathrm{~m} \mathrm{~s}^{-1}$. The resultant incident bar contact and striker bar contact stresses-strain curves are shown in Fig. 16(b) together with the stressstrain curves of the same model with face sheet. As seen in the same figure, the front-face sheet has almost no effect on the contact stress profiles except it increases the distal end stress near the densification. It 
is also noted in Fig. 16(b) that the face sheet induces stress oscillations (ringing) in the initial region of the incident bar contact stress.

\subsection{Comparison with $r-p-p-l$ model}

The variations of the experimental and numerical distal end initial crushing stresses and numerical impact end stresses (Fig. 15(b) and (d)) with the velocity are shown in Fig. 17(a). As is seen in the same figure, the distal end initial crushing stress increases from 1.25 MPa at quasistatic velocity to nearly $2 \mathrm{MPa}$ at about $20 \mathrm{~m} \mathrm{~s}^{-1}$, thereafter it saturates at $\sim 2 \mathrm{MPa}$. The rigid-perfectly-plastic-locking (r-p-p-l) model of the direct impact peak stress $\left(\sigma^{*}\right)$, stress $(\sigma)$ and velocity $(v)$ relations are given sequentially as [4]

$\sigma^{*}=\sigma_{p}+\frac{\rho_{o}}{\varepsilon_{d}} v^{2}$

and

$\sigma(t)=\frac{\left(\frac{M}{A_{o}}\right)^{2}\left(\sigma_{p}+\frac{\rho_{0}}{\varepsilon_{d}} v_{o}^{2}\right)}{\left(\frac{M}{A_{o}}+\frac{\rho_{o} u}{\varepsilon_{d}}\right)^{2}}$

$v=\sqrt{\frac{\varepsilon_{d}}{\rho_{o}\left[\frac{\left(\frac{M}{A_{o}}\right)^{2}\left(\sigma_{p}+\frac{\rho_{o}}{\varepsilon_{d}} v_{o}^{2}\right)}{\left(\frac{M}{A_{o}}+\frac{\rho_{o} u}{\varepsilon_{d}}\right)^{2}}-\sigma_{p}\right]}}$

In above equations, $\sigma_{p}$ is the plateau stress, $v_{o}$ is the initial velocity, $\rho_{o}$ is the initial density, $A_{o}$ is the area, $u$ is the displacement, $\varepsilon_{d}$ is the densification strain and $M$ is the weight of the striker. The calculated rp-p-1 model stress-time (Eq. (10)) and velocity-time (Eq. (11)) history at $90 \mathrm{~m} \mathrm{~s}^{-1}$, using the quasi-static plateau stress of $0.96 \mathrm{MPa}$ and the dynamic plateau stress of $2 \mathrm{MPa}$ (modified) are shown in Fig. 17(b) together with the fully imperfect model stress-time and velocity-time history. Using the quasi-static plateau stress, the r-p-p-l model predicts lower crushing stresses than the fully imperfect model as depicted in Fig. 17(b). On the other side, the r-p-p-l model stresses are very similar to those of the fully imperfect model stresses when the plateau stress is taken as the dynamic plateau stress. Furthermore, the r-p-p-1 model based on the dynamic plateau stress also gives very similar velocitytime profile (Fig. 17(b)) with the fully imperfect model and the impact end stress values (Fig. 17(a)) with the fully imperfect and two-layer imperfect model.

By considering all the internal energy was due to the loss of the kinetic energy, the following equation was proposed for the critical velocity $\left(v_{c r}\right)$ for the shock formation [4]

$v_{c r}=\sqrt{\frac{2 \sigma_{p} \varepsilon_{d}}{\rho_{o}}}$

Taking $\sigma_{p}=0.96 \mathrm{MPa}, \rho_{0}=326 \mathrm{~kg} \mathrm{~m}^{-3}$ and $\varepsilon_{d}=0.72$ give a critical velocity of $\sim 65 \mathrm{~m} \mathrm{~s}^{-1}$. When $\sigma_{p}=2 \mathrm{MPa}$, the critical velocity increases to $94 \mathrm{~m} \mathrm{~s}^{-1}$. The later calculated critical velocity is well accord with the experimentally and numerically determined critical velocities for the shock formation. A sequential layer crushing is found in the test and fully imperfect model at $90 \mathrm{~m} \mathrm{~s}^{-1}$.

\section{Conclusions}

The crushing behavior of a layered $1050 \mathrm{H} 14$ aluminum corrugated core was determined both experimentally and numerically at the velocities between 0.0048 and $90 \mathrm{~m} \mathrm{~s}^{-1}$. In order to simulate the velocitydependent crushing behavior, three different models were implemented: the perfect, the two-layer imperfect and the fully imperfect model. The fully imperfect model represented the homogenous distribution of the imperfections, while the two-layer imperfect model the localized imperfections. The deformation was a homogenous mode between 0.0048 and $22 \mathrm{~m} \mathrm{~s}^{-1}$. The crush bands formed randomly at the weakest fin layer and progressed non-sequentially to uncrushed parts. A transition mode was found between 22 and $60 \mathrm{~m} \mathrm{~s}^{-1}$. In this mode, the crush bands were concentrated at the impact end and the strain in the crush bands was wider and did not reach the densification strain. A shock mode was determined at $90 \mathrm{~m} \mathrm{~s}^{-1}$ in which the layer crushing initiated at the impact end and progressed sequentially. The two-layer imperfect model well predicted both the stress-time profile and the layer crushing mode of the homogeneous and transition modes, while the stress-time profile and the layer crushing mode of the shock mode by the fully imperfect model. The fully imperfect model resulted in complete-sequential layer crushing at 75 and $90 \mathrm{~m} \mathrm{~s}^{-1}$. The layer crushing in the transition and shock mode started from the impact end regardless the perfect or imperfect models were implemented. The imperfect layers in the shock mode only affected the distal end stresses, while all models implemented resulted in similar impact end stresses. The experimental and model distal end initial crushing stresses increased with increasing velocity from quasi-static to about $22 \mathrm{~m} \mathrm{~s}^{-1}$. The increase of the initial crushing stress was ascribed to the micro inertial effect. The r-p-p-1 model based on the dynamic plateau stress well predicted the stress-time and velocity-time profile in the shock mode. Finally, the critical velocity for the shock deformation, $\sim 94 \mathrm{~m} \mathrm{~s}^{-1}$, was well accord with the experimentally and numerically determined critical velocities for the shock deformation.

\section{Acknowledgments}

The authors would like to thank Cumhur Akar for providing corrugated aluminum samples.

\section{References}

[1] H.N.G. Wadley, Multifunctional periodic cellular metals, Philos. Trans. R. Soc. AMath. Phys. Eng. Sci. 364 (1838) (2006) 31-68.

[2] D. Ruan, G. Lu, B. Wang, T.X. Yu, In-plane dynamic crushing of honeycombs - a finite element study, Int. J. Impact Eng. 28 (2) (2003) 161-182.

[3] Z.J. Zheng, J.L. Yu, J.R. Li, Dynamic crushing of 2D cellular structures: a finite element study, Int. J. Impact Eng. 32 (1-4) (2005) 650-664.

[4] P.J. Tan, S.R. Reid, J.J. Harrigan, Z. Zou, S. Li, Dynamic compressive strength properties of aluminium foams. Part II - 'shock' theory and comparison with experimental data and numerical models, J. Mech. Phys. Solids 53 (10) (2005) 2206-2230.

[5] K. Li, X.L. Gao, J. Wang, Dynamic crushing behavior of honeycomb structures with irregular cell shapes and non-uniform cell wall thickness, Int. J. Solids Struct. 44 (14-15) (2007) 5003-5026.

[6] Y.D. Liu, J.L. Yu, Z.J. Zheng, J.R. Li, A numerical study on the rate sensitivity of cellular metals, Int. J. Solids Struct. 46 (22-23) (2009) 3988-3998.

[7] Z. Zou, S.R. Reid, P.J. Tan, S. Li, J.J. Harrigan, Dynamic crushing of honeycombs and features of shock fronts, Int. J. Impact Eng. 36 (1) (2009) 165-176.

[8] X.C. Zhang, Y. Liu, B. Wang, Z.M. Zhang, Effects of defects on the in-plane dynamic crushing of metal honeycombs, Int. J. Mech. Sci. 52 (10) (2010) 1290-1298.

[9] Z.J. Zheng, Y.D. Liu, J.L. Yu, S.R. Reid, Dynamic crushing of cellular materials: continuum-based wave models for the transitional and shock modes, Int. J. Impact Eng. 42 (2012) 66-79.

[10] A.T. Barnes, K. Ravi-Chandar, S. Kyriakides, S. Gaitanaros, Dynamic crushing of aluminum foams: part I - Experiments, Int. J. Solids Struct. 51 (9) (2014) 1631-1645.

[11] P.J. Tan, S.R. Reid, J.J. Harrigan, Z. Zou, S. Li, Dynamic compressive strength properties of aluminium foams. Part I - experimental data and observations, J. Mech. Phys. Solids 53 (10) (2005) 2174-2205.

[12] S.R. Reid, C. Peng, Dynamic uniaxial crushing of wood, Int. J. Impact Eng. 19 (5-6) (1997) 531-570.

[13] J.J. Harrigan, S.R. Reid, C. Peng, Inertia effects in impact energy absorbing materials and structures, Int. J. Impact Eng. 22 (9-10) (1999) 955-979.

[14] D.H. Zhang, Q.G. Fei, P.W. Zhang, In-plane dynamic crushing behavior and energy absorption of honeycombs with a novel type of multi-cells, Thin-Walled Struct. 117 (2017) 199-210.

[15] J.X. Qiao, C.Q. Chen, In-plane crushing of a hierarchical honeycomb, Int. J. Solids Struct. 85-86 (2016) 57-66.

[16] S.F. Liao, Z.J. Zheng, J.L. Yu, Dynamic crushing of 2D cellular structures: local strain field and shock wave velocity, Int. J. Impact Eng. 57 (2013) 7-16.

[17] S.L. Wang, Y.Y. Ding, C.F. Wang, Z.J. Zheng, J.L. Yu, Dynamic material parameters of closed-cell foams under high-velocity impact, Int. J. Impact Eng. 99 (2017) $111-121$.

[18] H. Liu, Z.Q. Zhang, H. Liu, J.L. Yang, Effect of elastic target on Taylor-Hopkinson impact of low-density foam material, Int. J. Impact Eng. 94 (2016) 109-119. 
[19] P.F. Wang, S.L. Xu, Z.B. Li, J.L. Yang, C. Zhang, H. Zheng, S.S. Hu, Experimental investigation on the strain-rate effect and inertia effect of closed-cell aluminum foam subjected to dynamic loading, Mater. Sci. Eng. A-Struct. Mater. Prop. Microstruct. Process. 620 (2015) 253-261.

[20] S. Gaitanaros, S. Kyriakides, On the effect of relative density on the crushing and energy absorption of open-cell foams under impact, Int. J. Impact Eng. 82 (2015) $3-13$.

[21] Y. Liu, W.W. Gong, X. Zhang, Numerical investigation of influences of porous density and strain-rate effect on dynamical responses of aluminum foam, Comput. Mater. Sci. 91 (2014) 223-230.

[22] S. Gaitanaros, S. Kyriakides, Dynamic crushing of aluminum foams: part II Analysis, Int. J. Solids Struct. 51 (9) (2014) 1646-1661.

[23] D. Karagiozova, G.S. Langdon, G.N. Nurick, Propagation of compaction waves in metal foams exhibiting strain hardening, Int. J. Solids Struct. 49 (19-20) (2012) 2763-2777.

[24] C. Kilicaslan, M. Guden, I.K. Odaci, A. Tasdemirci, Experimental and numerical studies on the quasi-static and dynamic crushing responses of multi-layer trapezoidal aluminum corrugated sandwiches, Thin-Walled Struct. 78 (2014) 70-78.

[25] C. Kılıçaslan, M. Güden, İ.K. Odacı, A. Tașdemirci, The impact responses and the finite element modeling of layered trapezoidal corrugated aluminum core and aluminum sheet interlayer sandwich structures, Mater. Des. 46 (0) (2013) 121-133.

[26] I.K. Odac, M. Guden, C. Klcaslan, A. Tasdemirci, The varying densification strain in a multi-layer aluminum corrugate structure: direct impact testing and layer-wise numerical modelling, Int. J. Impact Eng. 103 (2017) 64-75.

[27] V.S. Deshpande, N.A. Fleck, High strain rate compressive behaviour of aluminium alloy foams, Int. J. Impact Eng. 24 (3) (2000) 277-298.

[28] S. Heimbs, Virtual testing of sandwich core structures using dynamic finite element simulations, Comput. Mater. Sci. 45 (2) (2009) 205-216.

[29] D. Asprone, F. Auricchio, C. Menna, S. Morganti, A. Prota, A. Reali, Statistical finite element analysis of the buckling behavior of honeycomb structures, Compos. Struct. 105 (2013) 240-255.

[30] S. Lee, F. Barthelat, J.W. Hutchinson, H.D. Espinosa, Dynamic failure of metallic pyramidal truss core materials - experiments and modeling, Int. J. Plast. 22 (11) (2006) 2118-2145.

[31] C. Kilicaslan, M. Guden, I.K. Odaci, A. Tasdemirci, The impact responses and the finite element modeling of layered trapezoidal corrugated aluminum core and aluminum sheet interlayer sandwich structures, Mater. Des. 46 (2013) 121-133.
[32] I.K. Odaci, C. Kilicaslan, A. Tasdemirci, M. Guden, Projectile impact testing of glass fiber-reinforced composite and layered corrugated aluminium and aluminium foam core sandwich panels: a comparative study, Int. J. Crashworthiness 17 (5) (2012) $508-518$.

[33] $\mathrm{H}$. Kolsky, An investigation of the mechanical properties of materials at very high rates of loading, Proc. Phys. Soc. Sect. B 62 (11) (1949) 676-700.

[34] X. Wu, J., D, A. Gorham, Stress Equilibrium in the Split Hopkinson Pressure Bar Test, J. Phys. IV France 07(C3) C3-91-C3-96, 1997.

[35] H. Couque, The use of the direct impact Hopkinson pressure bar technique to describe thermally activated and viscous regimes of metallic materials, Philos. Trans. R. Soc. A-Math. Phys. Eng. Sci. 372 (2023) (2014) 10.

[36] R. Gumruk, S. Karadeniz, A numerical study of the influence of bump type triggers on the axial crushing of top hat thin-walled sections, Thin-Walled Struct. 46 (10) (2008) 1094-1106.

[37] G.R. Johnson, C. W.H, A constitutive model and data for metals subjected to large strains, high strain rates and high temperatures in: Proceedings of the 7th International Symposium on Ballistics. The Hague, The Netherlands, 1983, p. 541.

[38] S.P. Santosa, T. Wierzbicki, A.G. Hanssen, M. Langseth, Experimental and numerical studies of foam-filled sections, Int. J. Impact Eng. 24 (5) (2000) 509-534.

[39] D. Parry, J. P. Dixon, R, S. Hodson, N. Al-Maliky, Stress equilibrium effects within Hopkinson bar specimens, J. Phys. IV Fr. 04 (C8) (1994) (C8-107-C8-112).

[40] C.R. Calladine, R.W. English, Strain-rate and inertia effects in the collapse of 2 types of energy-absorbing structure, Int. J. Mech. Sci. 26 (11-1) (1984) (689-\&).

[41] H. Zhao, I. Elnasri, S. Abdennadher, An experimental study on the behaviour under impact loading of metallic cellular materials, Int. J. Mech. Sci. 47 (4-5) (2005) $757-774$.

[42] M. Langseth, O.S. Hopperstad, Static and dynamic axial crushing of square thinwalled aluminium extrusions, Int. J. Impact Eng. 18 (7-8) (1996) 949-968.

[43] A. Paul, U. Ramamurty, Strain rate sensitivity of a closed-cell aluminum foam, Mater. Sci. Eng. A-Struct. Mater. Prop. Microstruct. Process. 281 (1-2) (2000) 1-7.

[44] V.L. Tagarielli, V.S. Deshpande, N.A. Fleck, The high strain rate response of PVC foams and end-grain balsa wood, Compos. Pt. B-Eng. 39 (1) (2008) 83-91.

[45] D.G. Vaughn, J.M. Canning, J.W. Hutchinson, Coupled plastic wave propagation and column buckling, J. Appl. Mech. Trans. 72 (2005), pp. 139-146.

[46] G.J. McShane, S.M. Pingle, V.S. Deshpande, N.A. Fleck, Dynamic buckling of an inclined strut, Int. J. Solids Struct. 49 (19-20) (2012) 2830-2838. 